\title{
Estudo das espécies do "complexo Acaulona” sensu Sabrosky (Diptera, Tachinidae) ${ }^{1}$
}

Ronaldo Toma ${ }^{2}$

\begin{abstract}
Study of the species of the "Acaulona complex" sensu Sabrosky (Diptera, Tachinidae). Seven genera are treated: Acaulona Wulp, 1888 = Forcipophasia Townsend, 1935 syn. nov., Euacaulona Townsend, 1908, Itaxanthomelana Townsend, 1927, Melanorophasia Townsend, 1934, Urucurymyia Townsend, 1934, Xanthomelanopsis Townsend, 1917, and Mahauiella gen. nov. Two new species are described: Mahauiella nayrae sp. nov. (Brasil, Santa Catarina) and Mahauiella sforcini sp. nov. (Brasil, Santa Catarina). New synonyms proposed: Acaulona costata Wulp, 1888 = Forcipophasia fusca Townsend, 1935 syn. nov. = Acaulona brasiliana Townsend, 1937 syn. nov.
\end{abstract}

KeYwords. Acaulona complex; Gymnosomatini; Tachinidae; taxonomy; Trichopodini.

\section{INTRODUÇÃO}

SABrosky (1950) dividiu a tribo Trichopodini em três complexos genéricos: "Acaulona," "Trichopoda" e "Xanthomelanodes." As espécies do "complexo Xanthomelanodes" foram agrupadas pela presença de cerdas basais escutelares amplamente divergentes, bem maiores que as cerdas escutelares apicais, e posicionadas à meia distância entre a base do escutelo e a cerda apical; as do "complexo Acaulona," pela ausência de cerdas achatadas nas tíbias posteriores e as do "complexo Trichopoda," pela presença desse caráter.

Sete gêneros, com registros de distribuição neotropical, foram arrolados por SABROSKY (op. cit.) para constituir o “complexo Acaulona:" Acaulona Wulp, 1888; Euacaulona Townsend, 1908; Forcipophasia Townsend, 1935; Itaxanthomelana Townsend, 1927; Melanorophasia Townsend, 1934; Urucurymyia Townsend, 1934; Xanthomelanopsis Townsend, 1917.

Dupuis (1963), tratando o "complexo Acaulona" como uma subtribo, Acaulonina, excluiu Xanthomelanopsis e Melanorophasia desse grupo com base na diferença morfológica dos ovos. Apesar disso, para o propósito de estudo, esses gêneros são examinados aqui pelo fato dos adultos serem morfologicamente bastante similares aos dos demais gêneros do complexo, podendo facilmente ser confundidos com estes.

Registros de hospedeiros (Townsend 1913, 1937; MENDES 1938, 1959; SABROSKY 1950; BerRY 1951; PARKER et al. 1951;
Beingolea 1962; Chan \& Zapata 1965; Guimarães 1977) indicam que, pelo menos, duas espécies sul-americanas (A. brasiliana Townsend, 1937 e A. peruviana Townsend, 1913) são parasitóides importantes de diversas espécies de Dysdercus Boisduval (Hemiptera, Pyrrhocoridae). Estes percevejos são vulgarmente conhecidos como "manchadores" e causam apreciáveis prejuízos à cultura do algodão, em virtude da transmissão da moléstia denominada "podridão interna dos capulhos" (MeNDEs 1938).

O presente trabalho tem como objetivo revisar as espécies do "complexo Acaulona" com base na morfologia externa dos adultos e das terminálias masculina e feminina, redescrever as espécies conhecidas e descrever os táxons novos.

Acrônimos das instituições citados no trabalho: AMNH, American Museum of Natural History, New York; BMNH, The Natural History Museum, London; CNCI, Canadian National Collection of Insect, Ottawa; DZUP, Coleção de Entomologia Pe. Jesus Santiago Moure, Departamento de Zoologia, Universidade Federal do Paraná, Curitiba; INPA, Instituto Nacional de Pesquisas da Amazônia, Manaus; MPEG, Museu Paraense Emílio Goeldi, Belém; USNM, United States National Museum of Natural History, Washington, D.C.

A terminologia empregada para morfologia segue MCALPINE (1981)e SABRosky (1950).

\section{“Complexo Acaulona” sensu Sabrosky, 1950}

Características gerais. Cabeça mais larga que o tórax; em vista lateral, trapezóide com a fronte levemente abaulada; olhos

\footnotetext{
1. Parte do trabalho desenvolvido no Museu de Zoologia da Universidade de São Paulo (auxílio FAPESP).

2. Museu de Zoologia, Universidade de São Paulo. Caixa Postal 42694, 04299-970 São Paulo-SP, Brasil.
} 
amplamente separados em ambos os sexos; vibrissa a meia distância entre o término do flagelômero e a margem oral, esta levemente projetada; flagelômero oval ou subelíptico; palpo amarelo ou laranja e levemente clavado; gena cerca de um oitavo da altura do olho; faciália, em geral, sem cerdas acima da vibrissa ou com pequenas cerdas adjacentes a esta; cerdas ocelares divergentes; cerdas verticais externas, ausentes e cerdas verticais internas, em geral, menores que as cerdas pós-ocelares.

Tórax com coloração variando do pardo-alaranjado ao castanho-escuro; laterais e margem posterior do escuto e pleuras, às vezes, mais claras. Pré-escuto com três faixas longitudinais largas delimitadas por pruinosidade de colorido variado, com a faixa central subdividida ou não; pós-escuto com divisão das faixas não tão nítida e com a parte pré-escutelar bastante pruinosa. Acrosticais $0: 1$; dorsocentrais 1:2, 2:3 ou $3: 3$; intra-alares $0: 1$; supra-alares $1: 1$; catepisternais 2 ou 3 ; pós-pronotais 1 ou 2 . Escutelo com cerdas basais pouco maiores ou iguais às cerdas apicais, subparalelas e inseridas bem perto da base; cerdas laterais medianas ausentes. Pernas com colorido variando do pardo-alaranjado ao castanho-escuro, com a base dos fêmures, principalmente, médio e posterior, em geral mais clara; tíbia posterior sem fileira de cerdas achatadas e próximas umas das outras. Asa escura ao longo da veia Costal; veia Mediana com curvatura arredondada, fechada ou não na veia $\mathrm{R} 4+5$.

Abdome com colorido variando do amarelo ao castanhoescuro; em várias espécies com predominância do amarelo ou pardo-amarelado com manchas triangulares dorsais castanhas, direcionadas para frente; com ou sem cerdas marginais medianas; cerdas discais ausentes.

Terminália do macho (Figs. 1-55). Cercos, em vista posterior, fusionados medianamente, com ou sem expansões laterais distais; parte apical com um processo mediano de formato variado; base cavada em 'V'; em vista lateral, processo mediano ultrapassando em comprimento as expansões laterais. Surstilos reduzidos, arredondados, ligados ao epândrio por uma membrana. Edeago alongado e recoberto externamente por uma membrana; em vista posterior, na parte médio-apical, deslocado para direita e logo em seguida para a esquerda; acrofalo formado por uma placa esclerotinizada em forma de cálice, com ducto espermático distal interno simples, bi- ou trifurcado; basifalo e epifalo em geral esclerotinizados, o último com ângulo e formato variados; apódema ejaculatório espatulado de largura variável.

Terminália da fêmea (Figs. 56-68). Sétimos tergito e esternito, em geral, não fusionados. Esternito 8, em geral, esclerotinizado e cercos de formato variado.

Comentários. Tschorsnig (1985), em seu estudo da morfologia do pós-abdome dos machos de Tachinidae, afirmou que as espécies de Phasiinae formavam um agrupamento natural com base no caráter apomórfico: região mediana do hipândrio bem alongada de ambos os lados e com o gonópodo posicionado posteriormente a ela. Dentro dessa subfamília, delimitou Gymnosomatini como natural. Algumas das características assinaladas para essa tribo foram verificadas nas espécies do "complexo Acaulona" e em alguns táxons dos dois outros complexos que puderam ser por mim examinados (Homogenea Wulp, 1892, Platyphasia Townsend, 1935, Bibiomima handlirschi Brauer \& Bergenstamm, 1889, pertencentes ao "complexo Trichopoda," e Xanthomelanodes Townsend, 1893 e Xenophasia Townsend, 1934, pertencentes ao "complexo Xanthomelanodes"), como: edeago, na região do acrofalo, com ducto espermático rígido e trifurcado apresentando um ou dois ductos reduzidos ou não - dentro de um invólucro complexo (exceto para o "complexo Xanthomelanodes," cujo edeago possui a região do acrofalo bastante assimétrica); cercos com um processo arredondado na extremidade terminal; apódema do edeago prolongando-se como membrana entre o edeago e o gonópodo + parâmero.

Por outro lado, uma bifurcação nas partes alongadas da região mediana do hipândrio com o posicionamento característico do gonópodo, caráter também assinalado por TsCHORSNIG (1985, Fig. 158) para Gymnosomatini, não ocorre nas espécies do "complexo Acaulona" nem nos táxons examinados dos dois outros complexos. Nesses táxons, o hipândrio apresenta apenas os alongamentos medianos e o prolongamento de seus próprios braços, estando o gonópodo posicionado na parte posterior dessas duas estruturas (Figs. 1,2). Com base nas características citadas por TsCHORSNIG (op. cit.), excetuando a última, é provável que a tribo Gymnosomatini sensu Tschorsnig equivalha às tribos Gymnosomatini + Trichopodini sensu Townsend.

Uma outra característica que pode ser postulada para Gymnosomatini sensu Tschorsnig é o contorno da parte médioapical do edeago, em vista dorsal, deslocado para a direita e logo em seguida para a esquerda. Essa forma pode ser consequência de uma rotação da parte médio-apical do edeago, pois em alguns exemplares foi possível ver nitidamente um enrolamento, a esta altura, do ducto espermático interno. No entanto, outros estudos são necessários para a sustentação desta suposição.

A separação das espécies de Trichopodini por SABROSKY (1950) em três complexos pode ser analisada como um solução de caráter prático e não como uma tentativa de formação de grupos naturais, exceto para o "complexo Xanthomelanodes", cujo edeago possui o acrofalo bastante assimétrico, característica encontrada somente nas espécies desse grupo.

As espécies do "complexo Acaulona" foram separadas das espécies do "complexo Trichopoda" pela ausência de características, como, por exemplo, ausência de cerdas achatadas nas tíbias posteriores. Por outro lado, algumas espécies do "complexo Acaulona" apresentam o padrão morfológico da terminália, tanto masculina quanto feminina, mais assemelhado ao padrão das terminálias das espécies do "complexo Trichopoda" do que ao do próprio complexo.

\section{Chave para os gêneros do "complexo Acaulona"}

1. Caliptra inferior com a borda lateral externa expandida na parte posterior, em forma de "bota"; asa, nos machos, com faixas de pruinosidade cinza próximo às veias $\mathrm{Sc}, \mathrm{R} 2+3 \mathrm{e} \mathrm{R} 4+5$........ Euacaulona Townsend 
Caliptra inferior com a borda lateral externa nunca como acima; asa, nos machos, em geral, sem pruinosidade ... 2

2(1). Veia M terminando na veia $\mathrm{R} 4+5$, formando externamente um ângulo entre 90 e $120^{\circ}$ e um pecíolo mais longo que a veia transversal r-m ...... Mahauiella gen. nov.

Veia $\mathrm{M}$, em geral, terminando próximo à margem da asa; se finalizando na veia $\mathrm{R} 4+5$, então com ângulo externo maior que $120^{\circ}$ e pecíolo menor que a veia transversal r-m

.... 3

3(2). Abdome com densa pruinosidade, principalmente na base dos tergitos, formando um anel visível a olho $\mathrm{nu}$, pelo menos nos tergitos 3 e 4

Urucurymyia Townsend

Abdome com ou sem pruinosidade; quando presente, mais concentrada nas laterais dos tergitos ........... 4

4(3). Dorsocentrais 1:2; cerdas marginais medianas, quando presentes, pouco distintas da cerdosidade do abdome Acaulona Wulp

Dorsocentrais 2:3 ou 3:3; se 1:2, então cerdas marginais medianas em geral distintas da cerdosidade do abdome 5

5(4). Tergitos abdominais com cerdas marginais medianas levemente mais distintas que a cerdosidade abdominal .... Melanorophasia Townsend

Tergitos abdominais, no mínimo, com um par de cerdas marginais medianas bem distintas da cerdosidade abdominal 6

6(5). Cerda dorsocentral pós-sutural anterior reduzida, não alcançando um terço do tamanho da última cerda dorsocentral pós-sutural

Itaxanthomelana Townsend

Cerda dorsocentral pós-sutural anterior mais curta que a posterior, porém distinta e mais que um terço do comprimento da última cerda dorsocentral póssutural Xanthomelanopsis Townsend.

\section{Acaulona Wulp, 1888}

Acaulona Wulp, 1888:4; Townsend, 1908:130 (chave); 1927:209 (chave), 1936:51 (chave); 1938:9 (redescrição); Sabrosky, 1950:361, 371 (nota, chave); Guimarães, 1971:6 (catálogo). Espécie-tipo: Acaulona costata Wulp, 1888, por monotipia.

Forcipophasia Townsend, 1935: 216; Sabrosky, 1950:362, 368 (chave, nota); Guimarães, 1971:7 (catálogo). Espécie-tipo: Forcipophasia fusca Townsend, 1935, por designação original. Syn. nov.

Diagnose. Parafaciália levemente mais estreita que a parafrontália. Flagelômero subelíptico e cerca de uma vez e meia o comprimento do pedicelo. Dorsocentrais $1: 2$, com as cerdas dorsocentrais pré-sutural e penúltima pós-sutural curtas. Caliptra inferior com a parte posterior levemente alargada; borda lateral externa sub-retilínea. Asas cerca de três vezes e meia mais longa que larga. Abdome, nos machos, alongado, levemente achatado ventralmente, em geral mais estreito apicalmente; nas fêmeas, pouco mais largo e dorsalmente convexo. Cerdas marginais medianas, quando presentes, pouco distintas, mais curtas que o dobro do comprimento das pequenas cerdas que cobrem o abdome. Fêmeas: esternito 8 preto, esclerotinizado, triangular, afilado da base para o ápice e recurvado para baixo; em vista lateral, a parte distal em ângulo reto com a parte basal. Machos: cercos com processo mediano apical subtriangular e expansões laterais distais subarredondadas e levemente convexas; parte lateral estreitando-se em direção à base. Edeago com uma membrana transparente na lateral esquerda, médio-apicalmente; acrofalo com uma placa esclerotinizada anterior grande e outra posterior menor; ducto espermático apical simples e corrugado; epifalo esclerotinizado, curto e anguloso, curvado para o dorso.

Comentários. Townsend (1935) propôs o gênero Forcipophasia para F. fusca Townsend, 1935, descrita com base num exemplar fêmea. SABROSKY (1950) supôs que, se sua interpretação sobre a descrição da terminália da fêmea em forma de fórceps estivesse correta, F. fusca poderia ser meramente uma fêmea de Acaulona costata. No entanto, não fez a sinonímia por desconhecer o exemplar-tipo. O holótipo, depositado no MZSP, encontra-se bastante danificado mas, pelas características das asas, abdome e terminália, não há dúvida de que Forcipophasia fusca Townsend, 1935 é um sinônimo de Acaulona costata, Wulp, 1888.

Chave para as espécies de Acaulona

1. Caliptra branca; pernas castanho-escuras; abdome com coloração geral castanho-escura; triângulo ocelar em geral com uma a quatro cerdas, cerca de 0,30 a 0,70 do comprimento das cerdas ocelares, posicionadas atrás dessas ................................... A. erythopyga Sabrosky

Caliptra amarela; se branca, então pelo menos a base das tíbias posteriores amarela ou amarelo-alaranjada; abdome com coloração geral variando do amarelo ao castanho-escuro; triângulo ocelar, em geral, sem cerdas posicionadas atrás das cerdas ocelares, se presentes, mais curtas que as cerdas supracitadas .. 2

2(1). Tergitos 5 e 6 com forte pruinosidade amarela ou amareloesbranquiçada ........................ . peruviana Townsend

Tergitos 5 e 6 com pruinosidade cinérea pouco notável A. costata Wulp

Acaulona costata Wulp, 1888

(Figs. 2, 3, 8, 9, 47-49, 56, 57)

Acaulona costata Wulp, 1888:4 (localidade-tipo: México, Vera Cruz, Medellín); Williston, 1908:361 (chave); Townsend, 1908:130 (comentário); Guimarães, 1971:6 (catálogo).

Forcipophasia fusca Townsend, 1935: 216 (localidade-tipo: Brasil, São Paulo, São Vicente); Sabrosky, 1950:362, 368 (chave, nota); 
Guimarães, 1971:7 (catálogo). Syn. nov.

Acaulona brasiliana Townsend, 1937:316 (localidade-tipo: Brasil, São Paulo, Campinas); Mendes, 1938:216 (hospedeiro); Sabrosky, 1950:369 (nota); Berry, 1951:34 (biologia e descrição da larva); Mendes, 1959:579,580 (hospedeiro); Blanchard, 1966:60, 61 (chave, redescrição); Guimarães, 1971:6 (catálogo). Syn. nov.

Diagnose. Pruinosidade da parafrontália, borda superior do occipício e escuto, em geral, amarelo-brilhante; da face, parafaciália e pleura, cinza levemente amarelada. Pernas castanhas, com coxas e base dos fêmures médio e posterior amarelas ou castanho-alaranjadas; caliptra inferior amarela. Abdome variando do amarelo com manchas triangulares castanhas, dorsais e direcionadas para frente, ao castanhoalaranjado. Pruinosidade cinérea pouco notável.

Comprimento 5,0-7,0 mm.

Macho. Cabeça pardo-alaranjada com a parte superior da parafrontália mais escura. Pruinosidade da parafrontália e borda superior do occipício, em geral, amarelo-brilhante; da face, faciália, parafaciália e gena, cinza e levemente amarelada. Fronte castanho-escura, levemente mais larga perto do vértice e, às vezes, perto da base antenal. Triângulo ocelar castanho-escuro com densa pruinosidade marrom-ferrugínea. Antena alaranjada, com a parte anterior do flagelômero castanha. Arista castanha, metade basal alaranjada ou não. Parafrontália cerca da metade ou pouco menos da metade da largura da fronte, medida na altura mediana da última. Pró-fronte pouco mais larga que a metade da largura da fronte.

Tórax castanho-escuro; laterais e parte posterior do escuto, metade apical do escutelo e pleuras castanho-alaranjados. Pruinosidade do escuto, em geral, amarelo-brilhante, da pleura, cinza e levemente amarelada. Pernas castanhas; coxas e base dos fêmures médio e posterior amarelas ou castanhoalaranjadas. Caliptra amarela.

Abdome variando do amarelo com manchas dorsais triangulares castanhas, direcionadas para frente, menos definidas nos tergitos 5 e 6 , ao castanho-alaranjado. Pruinosidade cinérea pouco notável.

Terminália. Edeago (Figs. 47,49) relativamente maior que o das demais espécies do gênero; cercos (Figs. 8, 9) com a concavidade abaulada entre o processo mediano apical e as expansões laterais; largura do apódema ejaculatório (Fig. 3), em geral, menor que a sua altura.

Fêmea. Abdome pouco mais largo e dorsalmente mais convexo. Terminália (Figs. 56, 57): sétimos tergito e esternito não fusionados. Cercos estreitos, alongados, mais afilados no ápice, próximos um do outro e posicionados subverticalmente (quando não projetados), recobrindo o esternito 8; ápice próximo à margem distal do esternito 7 .

Distribuição geográfica. México (San Luis Patosí) até Argentina.

Comentário. Acaulona costata é semelhante à A. peruviana, diferindo pela pruinosidade abdominal menos intensa e de coloração cinérea.

As terminálias masculina e feminina de $A$. brasiliana e $A$. costata não apresentam nenhuma diferença morfológica, sendo a primeira espécie considerada sinônimo júnior da última.

Material-tipo examinado. Acaulona costata Wulp, 1888 - Holótipo macho: MÉXICO, Vera Cruz: Medellín, I.1888, H.H.S. col. (BMNH, exemplar faltando o abdome, antenas e a perna posterior direita); Parátipo: MÉXICO, Vera Cruz: Orizaba, 1 fêmea, XII.1887, H.H.S. \& F.D.G. col. (BMNH, exemplar em bom estado, faltando a asa direita). Acaulona brasiliana - Síntipos: BRASIL, São Paulo: Campinas, 2 machos, 2 fêmeas, X.1936, Luis Mendes col. (MZSP, material em bom estado); idem, 1 fêmea, XI.1936 (MZSP, material em bom estado). Forcipophasia fusca - Holótipo fêmea: BRASIL, São Paulo: São Vicente, sem data, Barbiellini col. (MZSP, exemplar bastante danificado, sem a cabeça, reconhecível somente pela asa, abdome e terminália).

Material examinado. MÉXICO. San Luis Patosí (8 mi. Oeste Xilitla), 1 macho, 1 fêmea, 22-23.VII.1954, Univ. Kansas - Expedição México col. (CNC). Jalisco: La Primavera, 1 fêmea, 8.VII.1956, R. \& K. Dreisbach col. (CNC). Oaxaca: Donaji, 1 macho, 1 fêmea, 17.IV.1953, R.C. Bechtel, E.I. Schlinger col. (CNC). Vera Cruz: Acayucan, 1 fêmea, 23.X.1957, R. $\&$ K. Dreisbach col. (CNC). BRASIL. Pará: Serra Norte (Rio Salobo?), 1 macho, 24/27.VIII.1984 (MPEG); Santo Antônio (Belém-Brasília), 1 fêmea, 18.III, Pimentel col. (MPEG). Pernambuco: Vicência, 1 fêmea, 12.XI.1968, M. C. Arcanjo col. (MZSP). Mato Grosso: Chapada dos Guimarães, 1 fêmea, 18-16.XI.1983, E. Binda col. (INPA). Minas Gerais: Nova Resende, 1 macho, VI.1961, C. Elias col. (MZSP); Perdizes, 1 fêmea, 8.IV.1965, C. Elias col. (UFPR). Espirito Santos: Guarapari, 1 fêmea (UFPR). Rio de Janeiro: Itaguaí, 1 macho, XII.1978, J. R. Almeida col. (MZSP); Nova Friburgo (Mury), 1 fêmea, XII.1974, Gred \& Guimarães col. (MZSP); Resende (Fazenda Penedo), 1 macho, 21.VII.1959, H. S. Lopes col. (MZSP); Santo Antônio, Imbé, S. M. Madalena, 1 macho, VII.1960, M. Alvarenga col. (UFPR). São Paulo: Barueri, 2 machos, 3 fêmeas, 4 e 25.VI.1966, 30.I.1966, 1.VIII.1955, K. Lenko col. (MZSP); Cajuru (Cássia dos Coqueiros), 3 machos, IX.1954/ XI.1955, M. P. Barretto col. (MZSP); Caraguatatuba, 1 macho, 1 fêmea, 22.V-1.VI.1962, 1 fêmea 7-14.VII.1962, Exp. Dep. Zool col. (MZSP). Santa Catarina: Seara (Nova Teutônia), 3 machos, 3 fêmeas, I.1966, IX e X.1967, V.1971, F. Plaumann col (MZSP).

Acaulona erythopyga Sabrosky, 1950

(Figs. 12, 13, 50-52, 60, 61)

Acaulona erythopyga Sabrosky, 1950:370 (localidade-tipo: Porto Rico, Guayanilla); Guimarães, 1971:6 (catálogo).

Diagnose. Coloração geral castanho-escura; nas fêmeas, tergitos 5 e 6 e terminália amarelos ou amarelo-castanhos; nos machos, pelo menos as extremidades laterais do tergito $6 \mathrm{e}$ terminália castanho-alaranjadas. Pruinosidade delimitadora das faixas do escuto, pleura e abdome, cinza; neste mais nítida nas laterais das bordas distais dos tergitos 3,4 e 5 . Caliptra branca.

Comprimento 5,0-6,0 mm.

Macho. Cabeça pardo-amarelada com parafrontália mais escura. Pruinosidade da parafrontália e borda superior do occipício amarela; da face, faciália, parafaciália e gena, cinza e levemente amarelada. Fronte castanho-escura, estreitando-se do vértice até a altura anterior do triângulo ocelar e alargandose com menos intensidade em direção à pró-fronte. Triângulo ocelar com uma a quatro cerdas cerca de 0,30 a 0,70 do comprimento das cerdas ocelares e posicionadas atrás destas. Antena e arista castanho-escuras; base do flagelômero e ápice do pedicelo pouco mais claros. Parafrontália cerca da metade da largura da fronte, medida na altura mediana da última, e cerca da mesma largura da pró-fronte.

Tórax castanho-escuro com pleura levemente mais clara. 
Pruinosidade da pleura, do padrão de faixa do escuto e escutelo cinza. Pernas castanho-escuras; coxas, às vezes, mais claras. Caliptra branca, com a borda posterior externa relativamente mais arredonda que a interna.

Abdome castanho-escuro, com o tergito 6, terminália e, às vezes, laterais dos tergitos 4 e 5 amarelos ou amarelo-castanhos; pruinosidade cinza, mais visível nos tergitos 3, 4 e 5 .

Terminália. Difere das terminálias de $A$. costata e $A$. peruviana pelas expansões laterais apicais dos cercos (Figs. 12, 13) menores e mais abauladas e pelo edeago (Figs. 51-52) relativamente menor; de $A$. costata, também pelo apódema ejaculatório, em geral, com a largura equivalente à sua altura.

Fêmea. Abdome castanho-escuro com os tergitos 5 e 6 e terminália amarelos ou amarelo-castanhos, contrastando fortemente com o resto do abdome. Terminália (Figs. 60, 61): semelhante à de $A$.costata, diferindo pelos cercos levemente mais estreitos.

Distribuição geográfica. Porto Rico (Guayanilla, Guanajibo - próximo à Mayaguez).

Comentário. Difere das demais espécies do gênero pela coloração geral do abdome, pela caliptra de coloração branca e pelas diferenças supracitadas da terminália masculina.

Material-tipo examinado. Holótipo macho: PORTO RICO, Guayanilla, 3.XI.1949, W. Gauld col. (USNM, n 60134; ex Dysdercus andreae). Parátipos: PORTO RICO, Guayanilla, 1 macho, 1 fêmea, 3.XI.1949, W. Gauld col. (BMNH, emergido 26.XI.1949-25.I.1950; ex Dysdercus andreae); idem, 1 macho (AMNH; ex Dysdercus andreae); idem, 1 fêmea, 30.XI.1949 (AMNH, emergido 22.XII.1949 - 16. I.1950; ex Dysdercus andreae); idem, 1 fêmea, 26.VIII.1949 (CNC, emergido 26-30.IX.1949; ex Dysdercus andreae).

Acaulona peruviana Townsend, 1913

(Figs. 10, 11, 53-55, 58, 59)

Acaulona peruviana Townsend, 1913:93, (localidade-tipo: Peru, Piuri, Vale Chira, San Jacinto); Townsend, $1928: 7$ (ilustrações); Sabrosky, 1950:369 (redescrição, designação de neótipo); Berry, 1951:338 (biologia, descrição da larva); Guimarães, 1971:6 (catálogo); Toma, 2002:286 (designação de lectótipo).

Diagnose. Pruinosidade da parafrontália, borda superior do occipício e escuto amarelo-brilhante; da face, parafaciália e pleura, cinza e levemente amarelada. Coxas, base dos fêmures, caliptra e abdome amarelo-claros. O último com manchas triangulares castanhas, direcionadas para frente, e forte pruinosidade amarela nos tergitos 5 e 6 .

Comprimento $6,0 \mathrm{~mm}$.

Macho. Cabeça pardo-amarelada com a parte superior da parafrontália mais escura. Pruinosidade da parafrontália e parte superior da fronte amarelo-brilhante; da face, faciália e gena, cinza e levemente amarelada. Fronte castanho-escura; largura quase constante, levemente estreitada medianamente. Triângulo ocelar mais escuro, com pruinosidade marromferrugínea. Antena castanho-alaranjada com a parte anterior do flagelômero mais acastanhada. Arista castanha, às vezes, com a metade basal alaranjada. Parafrontália cerca da metade da largura da fronte, medida na altura mediana da última. Prófronte cerca de pouco mais da metade da largura da fronte.

Tórax com escuto e, às vezes, parte basal do escutelo, castanho-escuros; laterais e parte posterior do escuto, metade apical do escutelo e pleura, castanho-amarelados. Pruinosidade do escuto amarelo-brilhante, da pleura e escutelo cinza e levemente amarelada, do último às vezes marrom-ferrugínea. Pernas castanhas; coxas e base dos fêmures médio e posterior, amarelo-claras. Caliptra amarela.

Abdome amarelo-claro com manchas triangulares castanhas dorsais, direcionadas para frente, ausentes no tergito 6 . Pruinosidade amarela forte nos tergitos 5 e 6 .

Terminália semelhante à de $A$. costata, diferindo pelo tamanho do edeago (Figs. 53-55) relativamente menor, pelos cercos (Figs. 10,11) com a concavidade ligeiramente mais profunda entre o processo mediano apical e as expansões laterais, e pela largura do apódema ejaculatório aproximadamente igual à sua altura.

Fêmea. Terminália (Figs. 58, 59) semelhante à de $A$. costata.

Distribuição geográfica. Peru (Sullana, Chincha, Zomate, Caña da Zamán, Chapairá).

Comentário. A. peruviana é semelhante à $A$. costata, diferindo desta pela coloração geral amarelo-clara, pela forte pruinosidade amarela nos tergitos 5 e 6 , pelo tamanho em geral menor e pela terminália do macho (Figs. 10,11, 53-55).

SABRosky (1950) afirmou que $A$. peruviana não havia sido formalmente descrita e que o nome havia sido estabelecido em conexão à figura publicada por TownSEND (1928). SABROSKY (op. cit.) redescreveu a espécie e designou um neótipo, um alótipo e dezessete neoparátipos, com base em exemplares coletados e identificados por Townsend. No entanto, alertado pessoalmente por Dupuis, SABrosky (1951), em uma nota, reconheceu que $A$. peruviana já havia sido descrita formalmente por TownSEND (1913). Na mesma nota, afirmou sobre a pertinência da designação do neótipo, visto que o macho e a fêmea designados como tipos no trabalho original e depositados no USNM estariam supostamente perdidos. No entanto, os síntipos foram encontrados na coleção do USNM e cedidos para estudo. Toma (2002) publicou uma nota invalidando a designação do neótipo feita por SABROSKY (1950) e indicou um lectótipo (macho) e um paralectótipo (fêmea) para Acaulona peruviana.

Material-tipo examinado. Lectótipo e paralectótipo: PERU, Piura: Chira Valley, San Jacinto, 1 macho e 1 fêmea, 29.X.1912, E. W. Rust col. (USNM, n 19477).

Material examinado. [Material estudado por Sabrosky: PERU. Rio Tambo, 1 macho, 31.V, Townsend col. (USNM), rotulado como "Neótipo", e 2 machos, 31.V, Townsend col. (AMNH, fls. Euphorbia), como "Neoparátipos"]. PERU. Lima, 1 macho, I.1940, J. Wille col. (MZSP); Rio Tambo, 1 macho, 31.V., Townsend col. (CNC, Fls Euphorbia).

\section{Euacaulona Townsend, 1908}

Euacaulona Townsend, 1908:131; Townsend, 1927 (chave); 1936:50 
(chave); 1938:17 (redescrição); Sabrosky, 1950:362,368 (nota, chave); Guimarães, 1971:7 (catálogo). Espécie-tipo: Euacaulona sumichrasti Townsend, 1908, por designação original.

Diagnose. Distância entre as bordas internas dos olhos na altura da pró-fronte cerca do dobro da largura do vértice. Parafaciália pouco mais larga que a parafrontália. Flagelômero subelíptico ou oval, cerca do dobro do comprimento do pedicelo. Dorsocentrais 1:2, com as cerdas pré-sutural e penúltima pós-sutural, curtas. Caliptra inferior com a borda lateral externa expandida na parte posterior. Asa cerca de duas vezes e meia mais longa que larga; nos machos, com faixas de pruinosidade cinza próximo às veias Subcosta, $\mathrm{R} 2+3$ e R4+5. Tergitos 3 e 4 com um par de cerdas marginais medianas distintas, mais que o dobro do comprimento das menores cerdas que cobrem o abdome. Edeago com o ducto espermático distal bifurcado.

Comentários. Euacaulona é monotípico; semelhante ao gênero Homogenea, arrolado no complexo Trichopoda, distingue-se deste pela ausência da fileira de cerdas achatadas nas tíbias posteriores e pelo edeago com o ducto espermático distal bifurcado.

Euacaulona sumichrasti Townsend, 1908

(Figs. 24, 25, 44-46, 66, 67)

Euacaulona sumichrasti Townsend, 1908:131 (localidade-tipo: México, Tehuantepec); Guimarães, 1971:7 (catálogo).

Diagnose. Colorido geral variando do amarelo ao castanhoescuro, com coxas, base dos fêmures, tíbias e parte ventral do abdome amarelos. Pruinosidade da cabeça, parte dorsal do abdome e escuto variando do amarelo-brilhante ao cinzaamarelado; da face, pleura, escutelo e laterais dos tergitos 3, 4 e 5, levemente acinzentada.

Comprimento 8,0-11,0 mm.

Macho. Cabeça pardo-alaranjada, mais escura na parafrontália. Pruinosidade amarelo-brilhante, levemente acinzentada na face. Fronte castanho-escura, levemente estreitada medianamente. Triângulo ocelar com pruinosidade marrom-ferrugínea. Antenas castanhas, com escapo e base do flagelômero levemente alaranjados; este, elipsóide, com a parte apical levemente mais larga que a basal. Arista castanha com a base levemente mais clara. Parafrontália pouco mais estreita que a metade da largura da fronte.

Tórax castanho-escuro com laterais do escuto e pleura mais claras; escutelo, às vezes, amarelado. Pruinosidade delimitadora das faixas do escuto amarelo-brilhante; da pleura e escutelo, mais acinzentada. Pernas castanho-escuras, com as coxas, base dos fêmures e das tíbias amarelas, de forma crescente no sentido anterior-posterior. Asa fosco-alaranjada ao longo da costa, escurecida na metade apical; superfície dorsal com pruinosidade cinza entre as veias Subcostal e Costal e próximo às veias $\mathrm{R} 2+3$ e R4+5; caliptra amarela.

Abdome alongado, subelíptico e achatado ventralmente; amarelo a castanho-escuro com a parte ventral amarelada e a apical, em geral, mais escurecida; pruinosidade variando do amarelo-brilhante ao cinza e mais concentrada nos tergitos $5 \mathrm{e}$ 6.

Terminália (Figs. 24, 25). Cercos com o processo apical mediano curto e expansões laterais apicais subarredondadas e discretas. Edeago (Figs. 44-46) com a parte esclerotinizada distal alongada, pouco menor que a metade do comprimento da altura total; ducto espermático distal bifurcado com um ducto longo e grosso, acompanhado em sua extensão por uma membrana e com uma ou duas estruturas aneladas apicalmente, e um ducto menor e mais estreito; epifalo reto e estreito da base para o ápice; apódema ejaculatório pouco mais largo que longo.

Fêmea (Euacaulona aff. sumichrasti ?). Parafrontália pouco mais da metade da largura da fronte; asa fosco-acastanhada sem a faixa de pruinosidade cinza entre as veias; abdome alongado e mais estreito posteriomente. Terminália (Figs. 66, 67). Sétimos tergito e esternito fusionados, formando um anel único; cercos subquadrangulares e posicionados sublateralmente, fechando-se para o meio, em geral cobertos pelo esternito 8; este curvado em sua base para cima e subarredondado no ápice. Catarina).

Distribuição geográfica. México (Tehunteapec), Brasil (Santa

Comentário. Exemplares fêmeas, listados no material examinado, enquadram-se no gênero Euacaulona, quando analisados pela chave de SABROSKY (1950), e podem pertencer a E. sumichrasti, quando comparados com os machos dessa espécie. No entanto, devido à associação com os machos ser uma suposição, os exemplares fêmeas são identificados apenas como E. affinis sumichrasti.

Material-tipo examinado. Holótipo macho. MÉXICO. Oaxaca: Tehuantepec, Sumichrast, sem data, sem coletor, (USNM, ${ }^{\circ} 10879$, exemplar faltando a asa esquerda, perna posterior esquerda e pernas anterior e média direitas).

Material examinado. GUIANA. Kamakusa, 2 machos, IX.1922, H. Lang col., (AMNH); Mazaruni (Low Forest), 1 fêmea, 28.VIII.1927, Richard \& Smart col. (BMNH); Kartabo (Road Side), 1 fêmea, 17.IX.1937, Richard \& Smart col. (BMNH); BRASIL. Amazonas: Manaus, Reserva Ducke (26 km Norte de Manaus), 2 fêmea, 1620.IX.1982, J. A. Rafael col. (INPA). Santa Catarina: Seara (Nova Teutônia), 2 machos, 16.XII.1938 e 7.I.1939, F. Plaumann col., (BMNH); idem, 1 macho, 25.I.1937, (AMNH); idem, 1 macho, 6.III.1936, (CNC). Paraná: Foz do Iguaçu, I.1962, 1 macho, Sakagami \& Laroca col. (DZUP).

Itaxanthomelana Townsend, 1927

Itaxanthomelana Townsend, 1927:214; 1936:50 (chave); 1938:21 (redescrição); Sabrosky, 1950:362, 368 (chave, nota); Guimarães, 1971:8 (catálogo). Espécie-tipo: Itaxanthomelana grandis Townsend, 1927, por designação original.

Diagnose. Distância entre as bordas internas dos olhos na altura da pró-fronte cerca de uma vez e meia ou menos a largura do vértice. Dorsocentrais $2: 3$, às vezes com as cerdas anteriores pré- e pós-suturais dorsocentrais reduzidas. Parte posterior da caliptra inferior sub-retangular, estreitando-se para frente. Asa 
cerca de duas vezes e meia mais longa que larga. Abdome alongado e subcilíndrico, alargando-se suavemente até o terço apical, levemente achatado ventralmente e convexo dorsalmente; nos machos, cerca de três vezes e meia e nas fêmeas cerca de duas vezes e meia mais longo que largo. Sintergito $1+2$, em geral, com um par de cerdas marginais medianas não muito distintas da cerdosidade do tergito. Tergitos 3, 4 e 5 com uma fileira de cerdas marginais medianas em geral bem distintas e espaçadas, os pares centrais mais conspícuos.

Itaxanthomelana grandis Townsend, 1927

(Figs. 22, 23, 26-28, 64, 65)

Itaxanthomelana grandis Townsend, 1927:322 (localidade-tipo: Brasil, São Paulo, Itaquaquecetuba); Guimarães, 1971:8 (catálogo).

Diagnose. Cabeça pardo-alaranjada, mais escura na parafrontália. Parafaciália cerca de um terço da largura da fronte na altura mediana da última. Tórax castanho-escuro, com pleura e laterais do escuto mais claras. Pernas, em geral, castanhoalaranjadas; base dos fêmures, amarela. Abdome amarelo com manchas triangulares castanho-escuras no sintergito $1+2 \mathrm{e}$ tergitos 3 e 4; tergito 5 e parte anterior do sintergito $1+2$, castanhos.

Comprimento 8,0-9,0 mm.

Macho. Cabeça pardo-alaranjada, mais escura na parte superior da parafrontália. Pruinosidade cinza, às vezes, mais amarelada na parafrontália. Fronte castanho-escura, mais larga no vértice, estreitando-se suavemente até a metade e alargandose em menor intensidade em direção à base da antena. Antena e arista castanhas. Flagelômero cerca de uma vez e meia o comprimento do pedicelo. Parafrontália cerca de um terço da largura da fronte, medida na altura mediana da última.

Tórax castanho-escuro; pleura e laterais do escuto mais claras. Pruinosidade delimitadora do padrão de listras do escuto, cinza ou cinza-amarelada, da pleura, cinza e do escutelo marromferrugínea. Pernas em geral castanho-alaranjadas; base dos fêmures amarelada. Asa fosca na metade anterior ao longo da veia Costal e mais hialina posteriomente. Caliptra amareloesbranquiçada.

Abdome amarelo com manchas triangulares largas castanho-escuras no sintergito $1+2$ e tergitos 3 e 4 ; tergito 5 e parte anterior do sintergito $1+2$, castanhos. Pruinosidade cinza notável nas laterais e, às vezes, nas bordas distais dos tergitos 4 e 5 .

Terminália. Cercos (Figs. 22, 23) com o processo apical mediano longo, curvado posteriomente, achatado lateralmente; em vista lateral, mais largo apicalmente. Edeago (Figs. 26, 27) com a parte esclerotinizada distal quase tão larga quanto longa; ducto espermático distal com bifurcação incompleta; epifalo estreito apicalmente, direcionado para trás, seguindo a curvatura do basifalo. Apódema ejaculatório (Fig. 4) alargando-se abruptamente na parte distal.

Fêmea. Abdome cerca de duas vezes e meia mais longo que largo. Terminália (Figs. 64, 65). Sétimos tergito e esternito não fusionados. Cercos subquadrangulares, posicionados lateralmente, fechando-se para o centro, com as bordas internas tocando uma na outra (quando não projetadas), cobrindo o esternito 8, este relativamante curto, subtriangular e levemente esclerotinizado. do Sul)

Distribuição geográfica. Brasil (São Paulo, Santa Catarina e Rio Grande

Comentário. O padrão de coloração é semelhante ao de Melanorophasia minuscula Townsend, 1934, diferindo desta pelos cercos subquadrangulares da terminália da fêmea.

Um dos exemplares de Santa Catarina apresenta a largura da parafrontália maior que um terço em relação à fronte, no entanto, não foi possível, através de outros caracteres separálo de I. grandis.

Material-tipo examinado. Holótipo fêmea. BRASIL. São Paulo: Itaquaquecetuba, 1926, Townsend col. (USNM, material em bom estado).

Material examinado. BRASIL. Santa Catarina: Seara (Nova Teutônia), 2 machos, V e X.1967, F. Plaumann col. (MZSP). Rio Grande do Sul: Pelotas, 2 machos, 1 fêmea, II.1994, R. F. Peixoto col. (MZSP; ex Largus rufipennis).

\section{Melanorophasia Townsend, 1934}

Melanorophasia Townsend, 1934:205; Townsend, 1936:51 (chave); 1938:22 (redescrição); Sabrosky, 1950:362, 367 (chave, nota); Guimarães, 1971:8 (catálogo). Espécie-tipo: Melanorophasia minuscula Townsend, 1934, por designação original.

Diagnose. Distância entre as bordas internas dos olhos na altura da pró-fronte cerca de uma vez e meia a largura do vértice. Dorsocentrais 2:3, com cerdas bem desenvolvidas. Caliptra inferior com a parte posterior levemente alargada e subquadrangular. Abdome subcilíndrico e levemente achatado ventralmente; vista dorsal, sétimo tergito visível, subarredondado posteriormente, assemelhando-se ao sexto tergito dos machos de Acaulona.

Melanorophasia minuscula Townsend, 1934 (Fig. 68)

Melanorophasia minuscula Townsend, 1934:205, (localidade-tipo: Brasil, Pará, Urucurituba, Rio Tapajós); Sabrosky, 1950:367 (designação de lectótipo); Guimarães, 1971 (catálogo).

Diagnose. Coloração geral castanho-escura; cabeça pardoalaranjada; ápice do pedicelo, parte posterior do flagelômero, palpos e coxas alaranjados; partes laterais posterior e anterior, respectivamente, do sintergito $1+2$ e tergito 3 amareladas; caliptra amarelo-esbranquiçada.

Comprimento 7,0 mm.

Fêmea. Cabeça pardo-alaranjada. Pruinosidade geral cinza; da parafrontália, cinza e levemente amarelada. Fronte castanhoescura; mais larga no vértice que na base da antena. Antena castanho-escura com o ápice do pedicelo e parte posterior do flagelômero alaranjados; este cerca de uma vez e meia o comprimento do pedicelo. Parafrontália cerca de um terço da 
largura da fronte medida na altura mediana da última.

Tórax castanho-escuro; pleura e laterais do escuto pouco mais claras. Pruinosidade delimitadora do padrão de listras do escuto, amarelo-brilhante, da pleura, cinza e levemente amarelada e do escutelo, cinza e marrom-ferrugínea. Pernas castanho-escuras com coxas alaranjadas. Asa com veia $\mathrm{M}$ terminando na veia $\mathrm{R} 4+5$ pouco antes de alcançar a margem da asa . Caliptra amarelo-esbranquiçada.

Abdome castanho-escuro com partes laterais posterior e anterior, respectivamente, do sintergito $1+2$ e do tergito 3 amareladas. Tergitos abdominais com uma fileira de cerdas marginais pouco mais distintas que a cerdosidade dos tergitos.

Terminália (Fig. 68). Cercos visíveis em vista ventral, cobertos pelo sétimo tergito dorsalmente e com formato subretangular, cavado na sua borda interna.

Distribuição geográfica. Brasil (Pará).

Comentário. SABRoSKy (1950), examinando a série-tipo de M. minuscula, com a finalidade de escolher um lectótipo, notou que os três exemplares descritos por Townsend como machos eram, na realidade, fêmeas e que, por sua vez, não eram coespecíficas com os dois outros exemplares da mesma série descritos como fêmeas. SABrosky (op. cit.) escolheu como lectótipo a fêmea rotulada por Townsend como "Ht macho" e assim designado em TownSEND (1938:22).

Devido ao risco de danificar o material-tipo, este não foi dissecado. A descrição da terminália acima é baseada em SABrosky (1950) e no que foi possível observar externamente.

Material-tipo examinado. Lectótipo fêmea: BRASIL, Pará: Urucurytuba, Rio Tapajós, 13.IV, Townsend col. (USNM, material em bom estado, abdome pouco amassado).

\section{Urucurymyia Townsend, 1934}

Urucurymyia Townsend, 1934:206; Townsend, 1936:50 (chave); 1938:31 (redescrição); Sabrosky, 1950:362,367 (chave, nota); Guimarães, 1971:10 (catálogo). Espécie-tipo: Urucurymyia urna Townsend, 1934, por designação original.

Diagnose. Distância entre as bordas internas dos olhos na altura da pró-fronte cerca de uma vez e meia a largura do vértice. Dorsocentrais 2:3 com cerdas bem desenvolvidas. Asa, nos machos, com mancha de pruinosidade cinza no terço basal, além do padrão fosco ao longo da costa. Caliptra levemente alargada posteriormente, estreitando-se para frente, mais acentuadamente no lado externo. Abdome subelíptico e achatado ventralmente; densa pruinosidade, principalmente, na base dos tergitos, formando um anel visível a olho nu pelo menos nos tergitos 3 e 4; cerdosidade nos tergitos 3, 4 e 5, em geral, acompanhando a área sem pruinosidade. Tergitos abdominais com uma fileira de cerdas marginais medianas finas, com os pares centrais mais espessos.

Urucurymyia urna Townsend, 1934

(Figs. 6, 7, 41, 42, 43)
Urucurymyia urna Townsend, 1934:206 (localidade-tipo: Brasil, Pará, Urucurituba, Rio Tapajós); Guimarães, 1971:10 (catálogo).

Diagnose. Cabeça pardo-amarelada, mais escura na parafrontália. Antena alaranjada com o pedicelo e parte anterior do flagelômero acastanhados. Tórax castanho-escuro com a pleura e laterais do escuto mais claras. Pruinosidade do padrão delimitador de listras do escuto amarelo-brilhante; da pleura e escutelo, cinza. Abdome pardo-amarelado com manchas triangulares castanho-escuras largas nos tergitos 3, 4 e 5; tergito 6, castanho.

Comprimento 7,0 mm.

Macho. Cabeça pardo-amarelada, mais escura na parafrontália. Pruinosidade amarela, mais forte na parafrontália e parte superior da parafaciália. Fronte castanho-escura; com largura subconstante, alargando-se próximo ao vértice e à base da antena. Antena alaranjada com o pedicelo e parte anterior do flagelômero acastanhados. Flagelômero cerca de uma vez e meia o comprimento do pedicelo. Parafrontália cerca de um terço da largura da fronte medida na altura mediana da última.

Tórax castanho-escuro com a pleura e laterais do escuto mais claras. Pruinosidade do padrão delimitador de listras do escuto amarelo-brilhante; da pleura e escutelo, cinza. Pernas castanho-alaranjadas, as coxas e as posteriores mais claras. Asa com mancha de pruinosidade cinza no terço basal; caliptra branca.

Abdome pardo-amarelado com manchas triangulares castanho-escuras largas nos tergitos 3,4 e 5; tergito 6 castanho. Pruinosidade cinza forte no sintergito $1+2$ e base dos tergitos 3, 4 e 5, e marrom-ferrugínea mais discreta sobre as manchas triangulares.

Terminália. Cercos (Figs. 6, 7) com o processo apical mediano longo, achatado lateralmente e levemente curvado para trás. Edeago (Figs. 41, 42, 43) com a parte posterior do acrofalo com uma estrutura em parte membranosa e em parte subesclerotinizada, dobrada em forma de 'sanfona'; ducto espermático distal com uma bifurcação médio-apical e uma segunda bifurcação, menos visível, no ducto mais dorsal. Apódema ejaculatório mais longo do que largo.

Fêmea. Segundo descrição de Townsend (1934), difere do macho pela coloração da pruinosidade da cabeça mais acinzentada e pela ausência de mancha no terço basal da asa. Terminália, segundo SABROSKY (1950): cercos longos, delgados e afilados; oitavo esternito longo, fino, polido e curvado para trás no ápice.

Distribuição geográfica. Brasil (Pará).

Material-tipo examinado. Holótipo macho: BRASIL, Pará: Urucurytuba, IV.1932-1933, Townsend col. (USNM; sobre flores de Cordia; material em bom estado).

\section{Xanthomelanopsis Townsend, 1917}

Xanthomelanopsis Townsend, 1917a:126; Townsend, 1927:214; 1936:50 (chave); 1938:32 (redescrição); Sabrosky, 1950:362, 367 (chave, nota); Guimarães, 1971:11 (catálogo). Espécie-tipo: Xanthomelanodes peruanus Townsend, 1911, por designação 
original.

Diagnose. Dorsocentrais 2:3 ou 3:3 com as cerdas anteriores pré- e pós-suturais menores, porém distintas; penúltima póssutural dorsocentral, em geral, ultrapassando a metade do comprimento da última. Caliptra com a parte posterior mais estreita e subquadrangular. Asa cerca de duas vezes e meia mais longa que larga. Abdome subelíptico ou subcilíndrico e alongado; em vista lateral, alargado posteriormente; no macho, sintergito $1+2$ com ou sem um par de cerdas marginais medianas; demais tergitos com uma fileira de cerdas marginais medianas, mais espaçadas nos tergitos 3 e 4 ; tergito 3 , às vezes, com um só par.

Chaves para as espécies de Xanthomelanopsis

1. Abdome subelíptico e achatado dorsoventralmente; coloração castanho-escura com as partes laterais, entre o final do sintergito $1+2$ e o começo do tergito 4 , amarelas ou castanho-amareladas

X. brasiliensis Townsend

Abdome subcilíndrico e alongado; coloração amarela com manchas triangulares castanho-escuras ... 2

2(1). Parafrontália com pouco mais que a metade da largura da fronte e quase uma vez e meia a largura da parafaciália X. peruana (Townsend)

Parafrontália cerca da metade da largura da fronte e cerca da mesma largura da parafaciália

X. trigonalis (Wulp)

Xanthomelanopsis brasiliensis Townsend, 1917

(Figs. 18, 19, 29-31, 62, 63)

Xanthomelanopsis brasiliensis Townsend, 1917b: 233 (localidade-tipo: Brasil, Pará, Ananindéua, Benevides); Guimarães, 1971:11 (catálogo).

Diagnose. Parafrontália cerca de um quarto da largura da fronte e cerca da mesma largura da parafaciália. Coloração geral castanho-escura; coxas e partes laterais do abdome entre o final do sintergito $1+2$ e o começo do tergito 4 , amarelas ou castanho-amareladas. Flagelômero cerca de pouco mais que duas vezes o comprimento do pedicelo. Caliptra inferior preta com a base branca. Abdome subelíptico e achatado dorsoventralmente. Garra tarsal relativamente curta.

Comprimento 6,0-7,0 $\mathrm{mm}$.

Macho. Cabeça castanho-amarelada. Pruinosidade cinza, da parafrontália e borda superior do occipício, amarelobrilhante. Fronte castanho-escura, alargando-se em direção à antena. Esta castanho-escura, com a base do flagelômero e ápice do pedicelo mais claros. Flagelômero cerca de pouco mais de duas vezes o comprimento do pedicelo. Arista castanha, metade basal, às vezes, alaranjada. Parafrontália cerca de um quarto da largura da fronte e cerca da mesma largura da parafaciália. Esta mais estreita que a faciália.

Tórax castanho-escuro. Pruinosidade da pleura, escuto e escutelo cinza. Asa escura ao longo da veia Costa; duas faixas de pruinosidade cinza, uma entre as veias Subcostal e Costal e outra entre a metade basal da veia R1+2 e metade distal da veia R1. Caliptra inferior preta, com base branca. Pernas castanhoescuras; coxas amarelas ou castanho-amareladas; garra tarsal relativamente curta.

Abdome castanho-escuro com as partes laterais, entre o final do sintergito $1+2$ e o começo do tergito 4 , amarelas ou castanho-amareladas. Formato subelíptico, achatado dorsoventralmente. Sintergito $1+2$ com cerdas marginais medianas reduzidas ou ausentes; tergito 3 com um par de cerdas marginais medianas subiguais em comprimento às cerdas da fileira de marginas medianas dos tergitos 4 e 5 .

Terminália. Cercos (Figs. 18, 19) com o processo apical mediano longo, achatado lateralmente e fortemente curvado para trás; região entre o processo mediano apical e as expansões laterais dos cercos bem cavada. Edeago (Figs. 29-31) com a parte esclerotinizada distal tão larga quanto longa; epifalo curvado para o dorso; ducto espermático distal trifurcado. Apódema ejaculatório mais alto do que largo.

Fêmea. Terminália (Figs. 62, 63) com os cercos robustos e subtriangulares; posicionados suborizontalmente com os ápices levemente sobrepostos (quando não projetados). Esternito 8 levemente esclerotinizado, subtriangular, posicionado subverticalmente, com ápice levemente curvado para trás.

Distribuição geográfica. Brasil (Amapá, Amazonas, Pará).

Comentário. Xanthomelanopsis brasiliensis difere de $X$. trigonalis pelo formato do abdome subelíptico e dorsoventralmente achatado.

Material-tipo examinado. Holótipo macho: BRASIL, Pará: Ananindéua, Benevides, VII., Herbert H. Smith col. (AMNH).

Material examinado. BRASIL. Amazonas: Marãa, R. Japurá, Maguari, 1 macho, 3-7.X.1988, J. Dias col. (MPEG). Amapá: Serra do Navio, 1 macho, 14.V.1989, I. S. Gorayeb \& A. Henrique (MPEG).

\section{Xanthomelanopsis peruana (Townsend, 1911)}

Xanthomelanodes peruanus Townsend, 1911: 128 (localidade-tipo: Peru, Piura); Townsend, 1912: 302 (redescrição).

Xanthomelanopsis peruana; Townsend, 1917: 126; Guimarães, 1971: 11 (catálogo).

Diagnose. Parafrontália com pouco mais da metade da largura da fronte e visivelmente mais larga que a parafaciália. Abdome amarelo com machas triangulares castanho-escuras do sintergito $1+2$ ao tergito 5 .

Comprimento $7,0 \mathrm{~mm}$.

Fêmea. Cabeça pardo-amarelada coberta de pruinosidade cinza e levemente amarelada. Fronte castanha; estreitando-se do vértice até a região mediana, em seguida alargando-se suavemente até a base da antena. Antena castanha, com pedicelo mais alaranjado. Flagelômero cerca de uma vez e meia o comprimento do pedicelo. Parafrontália com pouco mais da metade da largura da fronte e visivelmente mais larga que a parafaciália. 
Tórax castanho-escuro; pleura e laterais do escuto mais claras. Pruinosidade do padrão delimitador das listras do escuto amarelo-brilhante, da pleura e escutelo, cinza. Caliptra amarela. Pernas castanho-alaranjadas.

Abdome amarelo com manchas triangulares castanhoescuras do sintergito $1+2$ ao tergito 5. Pruinosidade cinzaamarelada, exceto nas manchas triangulares.

Macho. Segundo redescrição de Townsend (1912), difere da fêmea pela pruinosidade amarelo-brilhante da cabeça e abdome.

Distribuição geográfica. Peru (Piura).

Comentário. Townsend (1911) descreveu esta espécie com base apenas no sistema reprodutivo da fêmea e nos ovos. Em 1912, o mesmo autor tornou a descrevê-la, utilizando características da coloração do corpo, e designou o exemplartipo da espécie. Townsend afirmou ter examinado numerosos exemplares de ambos os sexos. No entanto, o único material recebido para estudo foi o holótipo fêmea que está com o abdome danificado e sem a terminália, impossibilitando fazer um estudo mais detalhado no momento, importante para a comparação com as demais espécies do gênero.

Baseando-se em SABRosky (1950), a fêmea de X. peruana é similar à de Melanorophasia minuscula, embora os cercos sejam aproximadamente quadrados e o esternito 8, curto e inconspícuo.

Material-tipo examinado. Holótipo fêmea: PERU, Piura: 6.XI.1910, Townsend col. (USNM, $\mathrm{n}^{\circ}$ 15140; exemplar com o abdome destacado e sem os esternitos e a terminália).

Xanthomelanopsis trigonalis (Wulp, 1892)

(Figs. 20, 21, 32-34)

Xanthomela trigonalis Wulp, 1892:188 (localidade-tipo: México, Guerrero, Xucumanatlan).

Xanthomelanopsis trigonalis; Guimarães, 1971:11 (catálogo).

Diagnose. Parafrontália cerca da metade da largura da fronte e cerca da mesma largura da parafaciália. Coloração geral castanho-escura; abdome amarelo com padrão de manchas trangulares do sintergito $1+2$ ao tergito 4 ; tergito 5 e terminália castanho-escuros. Forte pruinosidade abdominal cinzaamarelada, em geral, concentrada nas partes laterais mais claras.

Comprimento $8,0 \mathrm{~mm}$.

Macho. Cabeça pardo-amarelada. Pruinosidade cinza; da parafrontália e borda superior do occipício, amarelo-brilhante. Fronte castanho-escura, levemente mais larga próximo ao vértice e à base da antena. Antena escura com o ápice do pedicelo alaranjado. Flagelômero menos de um vez e meia o comprimento do pedicelo. Arista castanha com a metade basal castanho-alaranjada. Parafrontália cerca da metade da largura da fronte medida na altura mediana desta; pró-fronte pouco mais que metade da largura da fronte. Parafrontália cerca da mesma largura da parafaciália.

Tórax castanho-escuro. Pruinosidade do padrão delimitador das listras do escuto amarelo-brilhante; da pleura, cinza e levemente amarelada na parte superior; do escutelo cinza, com a base marrom-ferrugínea. Dorsocentrais 3:3. Caliptra amareloesbranquiçada. Pernas castanho-escuras; trocanteres alaranjados.

Abdome amarelo com manchas triangulares do sintergito $1+2$ ao tergito 4 ; tergito 5 e terminália, castanho-escuros. Forte pruinosidade cinza e levemente amarelada. Formato subcilíndrico, alongado e posteriormente alargado em vista lateral.

Terminália. Semelhante à de I. grandis, diferindo por: cercos (Figs. 20,21) com a escavação mais profunda entre o processo mediano apical e as expansões laterais distais; processo apical dos cercos, em vista lateral, menos alargado e mais curvado; edeago (Figs. 32-34) com o ducto espermático distal não bifurcado.

Distribuição geográfica. México (Guerrero, Xucumantlan).

Comentário. Xanthomelanopsis trigonalis é mais semelhante à Itaxanthomelana grandis do que à $X$. brasiliensis, levantando suspeitas de serem as duas primeiras congenéricas.

Material-tipo examinado. Holótipo macho: MÉXICO, Guerrero: Xucumanatlan, 700ft, VII., H.H. Smith col. (BMNH; exemplar sem o flagelômero direito, pernas esquerdas média e posterior e asa direita; asa esquerda colada no suporte de papel).

\section{Mahauiella gen. nov.}

Espécie-tipo: Mahauiella nayrae sp. nov.

Diagnose. Coloração castanho-escura; parte látero-ventral da base dos tergitos com pruinosidade cinza. Cerdas ocelares pouco menores que as cerdas verticais internas. Arista com o terço basal espessado, afilando abruptamente em direção ao ápice. Asas com veia M terminando em R4+5 antes de alcançar a margem da asa, formando um pecíolo mais longo que a veia transversal r-m; caliptra com a parte interna sub-reta e parte externa e posterior subarredondada; máculas escuras na altura das veias $\mathrm{CuA} 2$ e transversal bm-cu, transversais r-m e dm-cu, sendo nesta última menos intensa.

Cometário. Na chave para os complexos genéricos de Trichopodini (Sabrosky 1950), Mahauiella sai no "complexo Acaulona". Contudo, ao ser analisado pela chave de gêneros desse complexo, não se enquadra em nenhum de seus táxons. Mahauiella distingue-se dos demais gêneros do "complexo Acaulona" pelos caracteres supracitados da asa.

Etimologia. O nome do gênero é uma homenagem ao Dr. Maurício Sforcin.

\section{Mahauiella nayrae sp. nov.} (Figs. 14, 15, 38-40)

Diagnose. Parafrontália cerca de um terço ou pouco mais da largura da fronte; pró-fronte cerca da metada da largura da 
fronte. Antena e arista castanho-escuras, flagelômero cerca do dobro do comprimento do pedicelo. Asas com ângulo formado entre o pecíolo da veia $\mathrm{R} 4+5$ e veia $\mathrm{M}$ com pouco menos de $120^{\circ}$. Abdome cerca de quatro vezes mais longo que largo.

Comprimento 4,5-5,0 mm.

Macho. Cabeça pardo-acastanhada com pruinosidade amarelo-brilhante, incluindo o triângulo ocelar, mais intensa na parafrontália e parafaciália. Parafrontália cerca de um terço ou pouco mais da largura da fronte; pró-fronte cerca da metada da largura da fronte; parafaciála cerca de um quarto da largura da fronte. Antena e arista castanho-escuras, flagelômero cerca do dobro do comprimento do pedicelo.

Tórax castanho-escuro; pruinosidade amarelo-brilhante; pleura com pruinosidade amarela e levemente acinzentada. Cerdas pós-pronotais 3, a mais interna reduzida ou não. Pernas castanhas ou castanho-escuras com coxas e base dos fêmures posteriores amarelas; tarsos e garras tarsais relativamente curtos. Asa com ângulo formado entre o pecíolo da veia R4+5 e veia $\mathrm{M}$ com pouco menos de $120^{\circ}$.

Abdome castanho-escuro com pruinosidade cinza nas

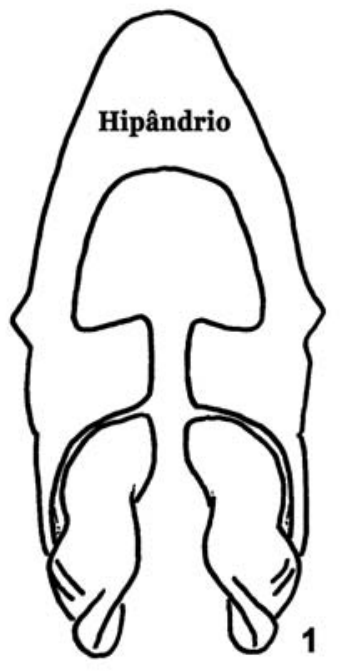

Gonópodo + Parâmero

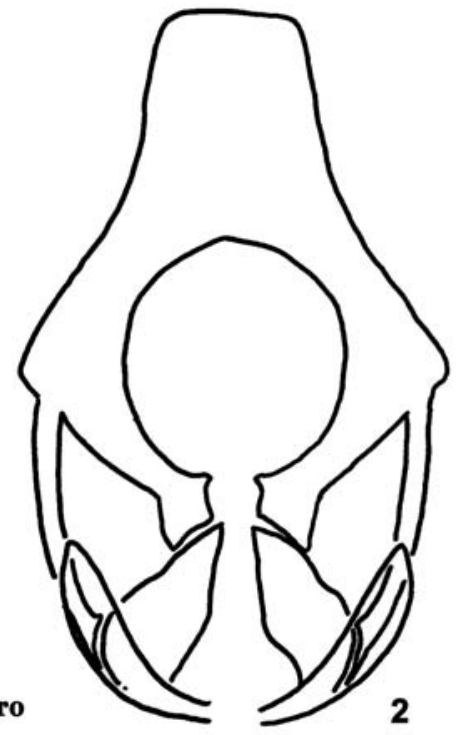

2
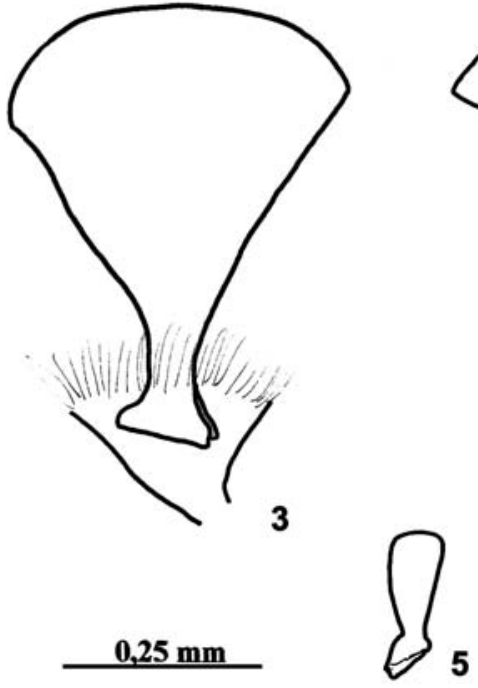

5
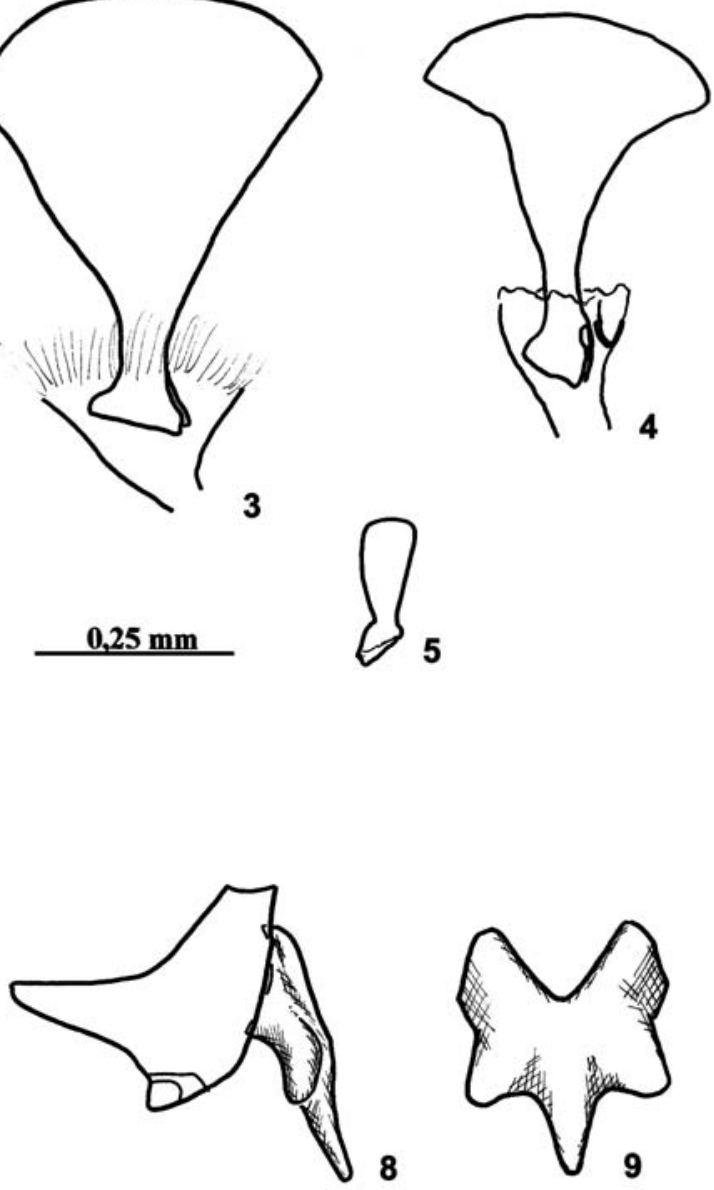

7
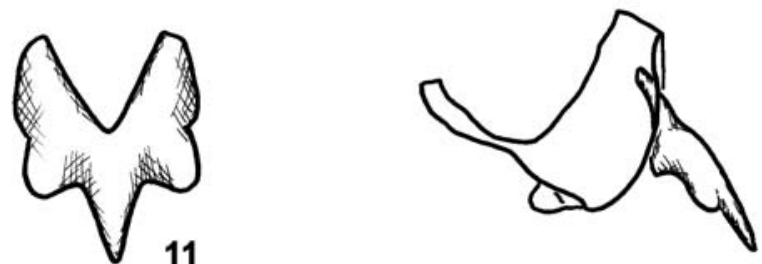

12

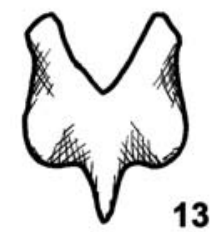

Figs. 1-13. 1-2. Hipândrio, gonópodo + parâmero: 1, Mahauiella sforcini sp. nov.; 2, Acaulona costata Wulp, 1888. 3-5. Apódema ejaculatório: 3, A. costata Wulp, 1888; 4, Itaxanthomelana grandis Townsend, 1927; 5, M. sforcini sp. nov. 6-13. Epândrio, surstilos e cercos (vista lateral) e cercos (vista posterior), respectivamente: 6-7, Urucurymyia urna Townsend, 1934; 8-9, Acaulona costata Wulp, 1888; 10-11, A. peruviana Townsend, 1913; 12-13, A. erythopyga Sabrosky, 1950. 
278

Toma
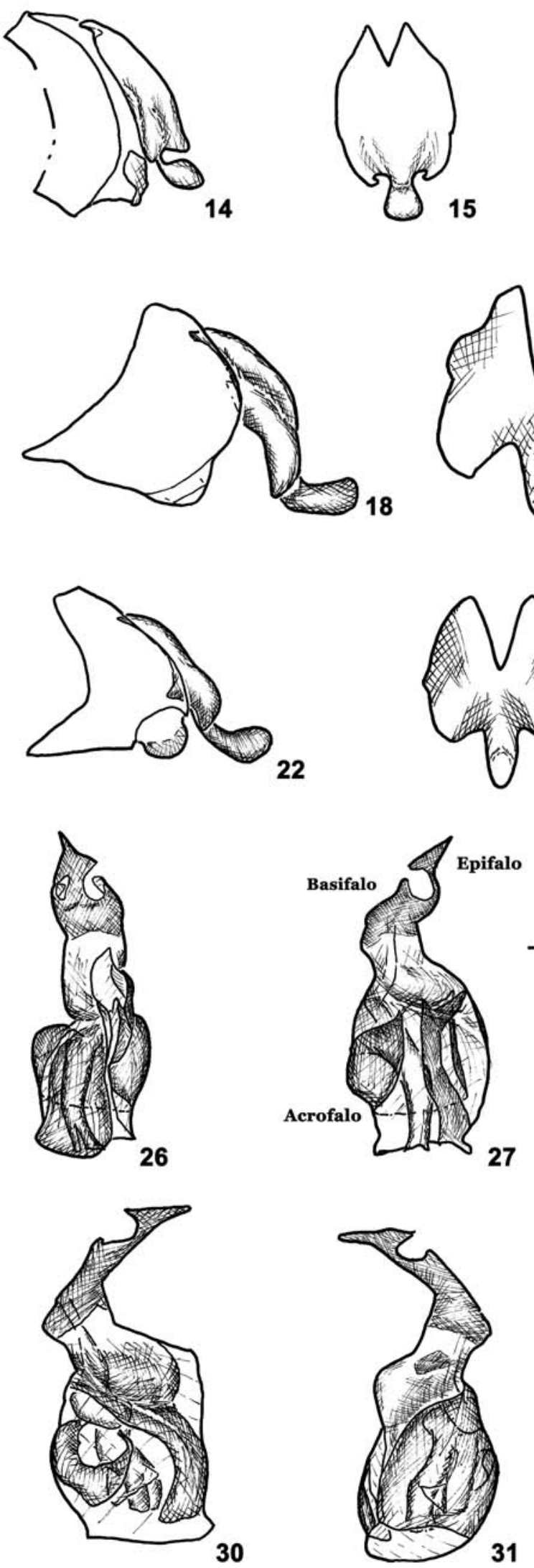
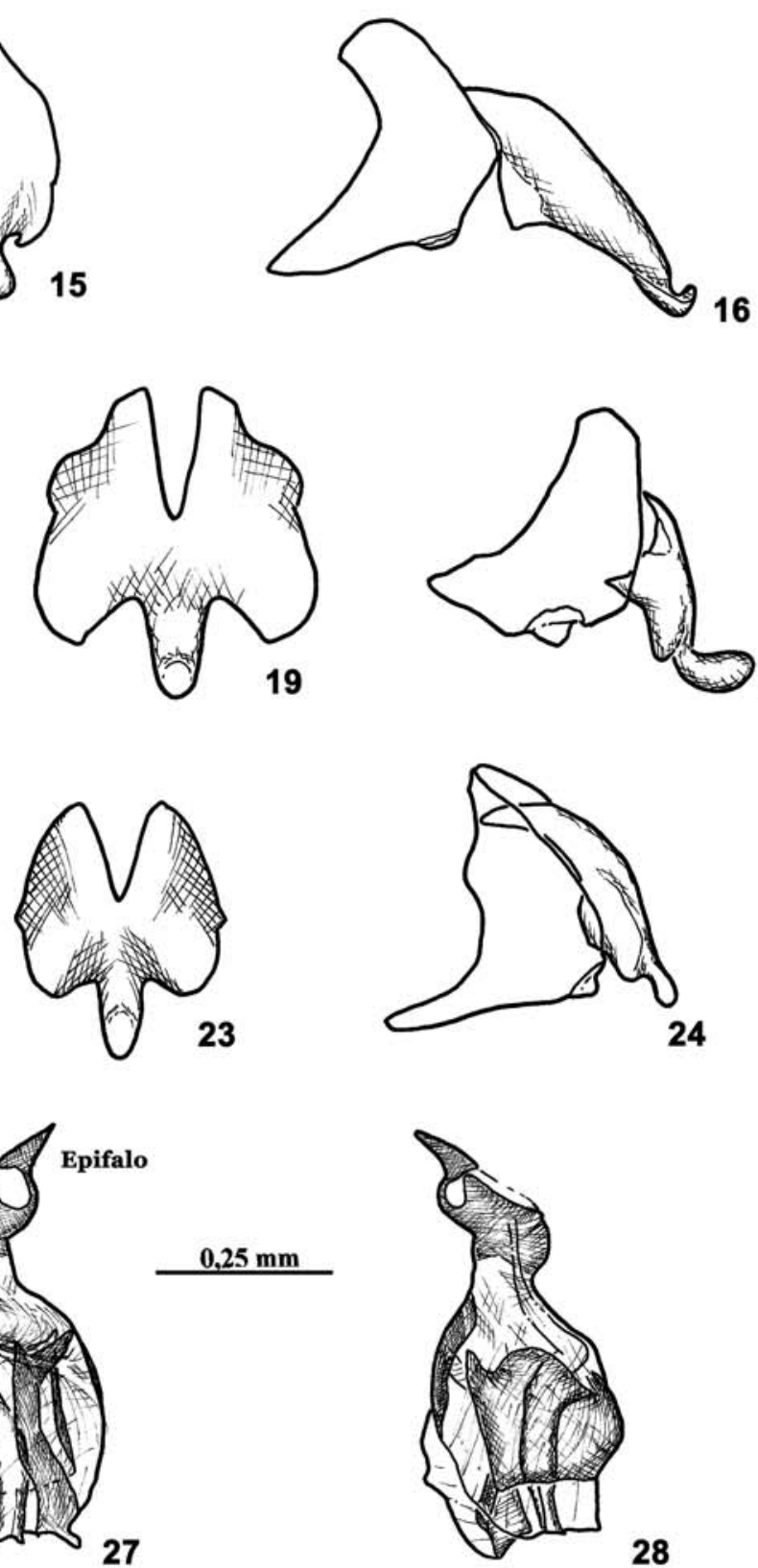

28

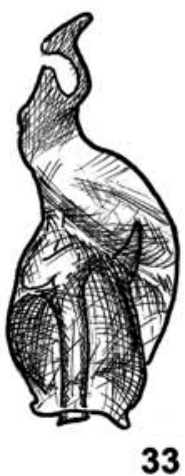

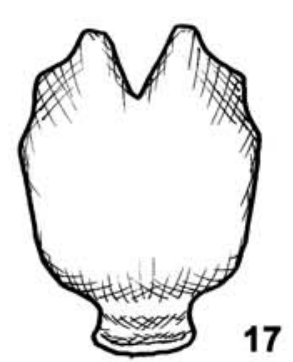

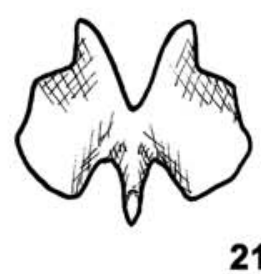

21

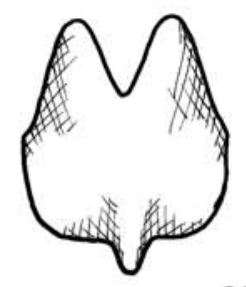

25

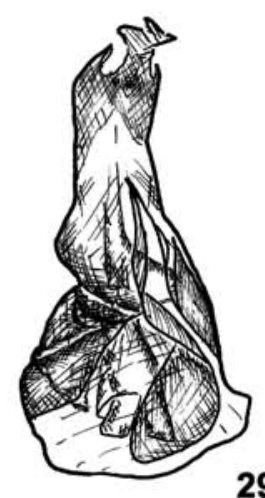

29

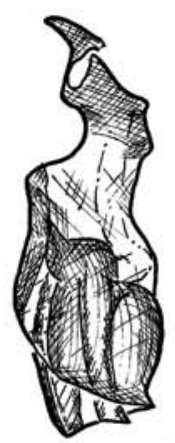

34

Figs. 14-34. Epândrio, surstilos e cercos (vista lateral) e cercos (vista posterior), respectivamente: 14-15, Mahauiella nayrae sp. nov.; 16-17, Mahauiella sforcini sp. nov.; 18-19, Xanthomelanopsis brasiliensis Townsend, 1917; 20-21, X. trigonalis (Wulp, 1892); 22-23, Itaxanthomelana grandis Townsend, 1927; 24-25, Euacaulona sumichrasti Townsend, 1908. 26-34. Edeago, vistas dorsal e laterais, respectivamente: 26-28, Itaxanthomelana grandis Townsend, 1927; 29-31, Xanthomelanopsis brasiliensis Townsend, 1917; 32-34, X. trigonalis (Wulp, 1892).

Revista Brasileira de Entomologia 47 (2), 2003 

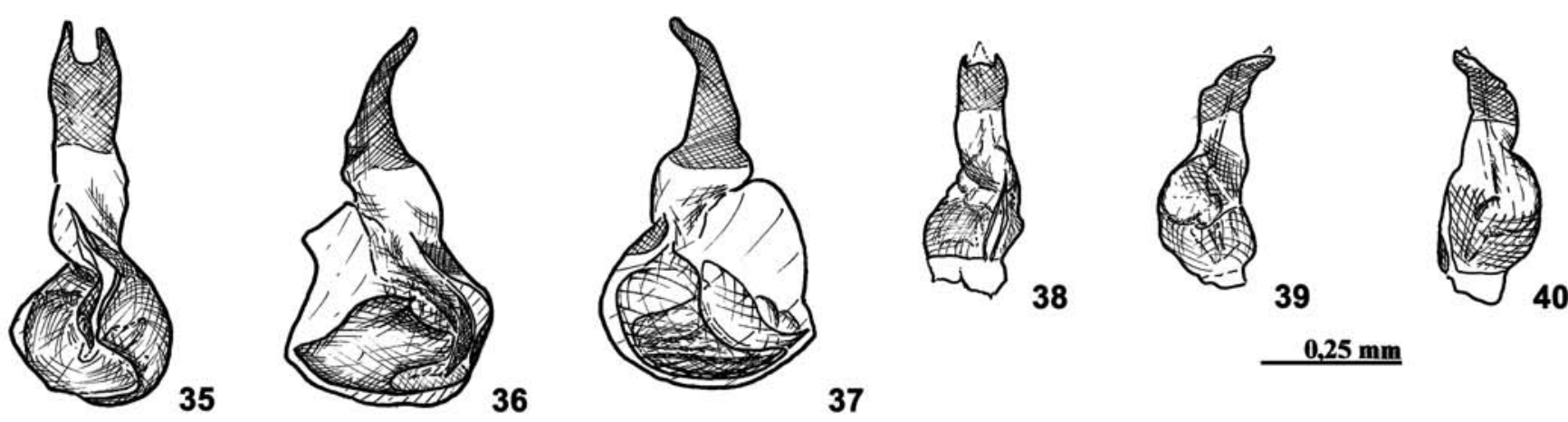

37
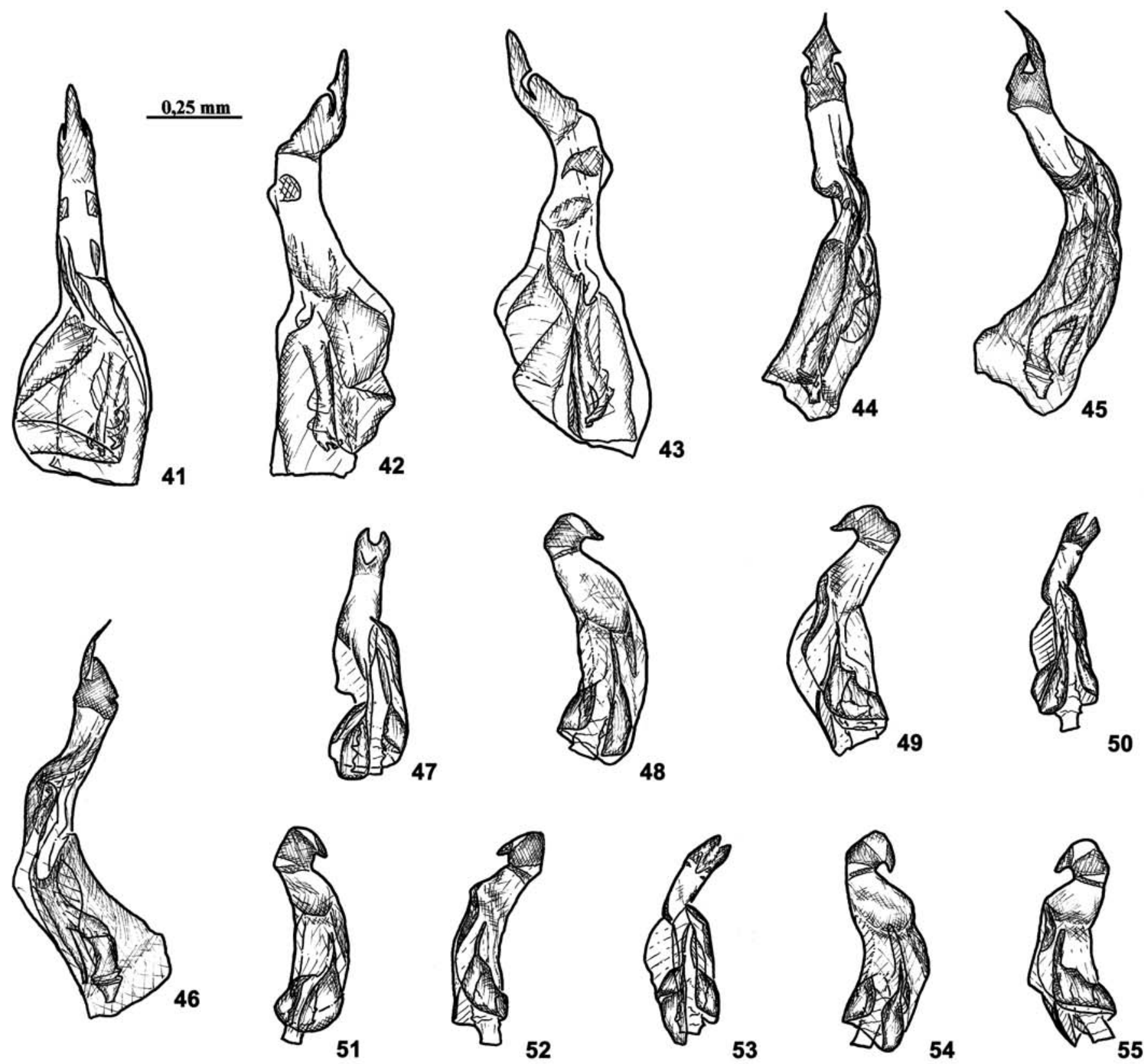

Figs. 35-55. Edeago, vistas dorsal e laterais, respectivamente: 35-37, Mahauiella sforcini sp. nov.; 38-40, Mahauiella nayrae sp. nov.; 41-43, Urucurymyia urna Townsend, 1934. 44-55. Edeago, vistas dorsal e laterais, respectivamente: 44-46, Euacaulona sumichrasti Townsend, 1908; 4749, Acaulona costata Wulp, 1888; 50-52, A. erythopyga Sabrosky, 1950; 53-55, A. peruviana Townsend, 1913. 


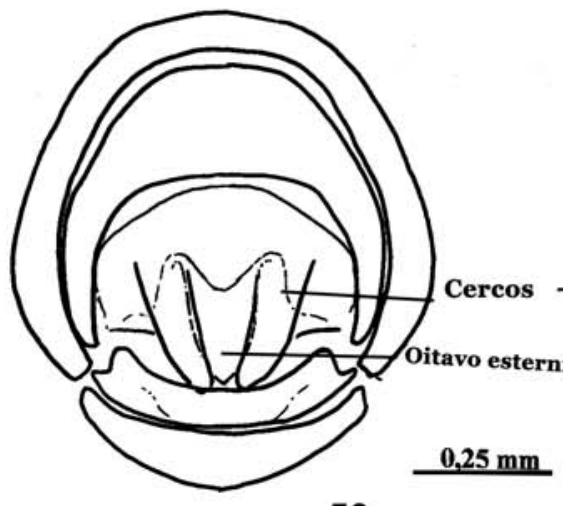

56

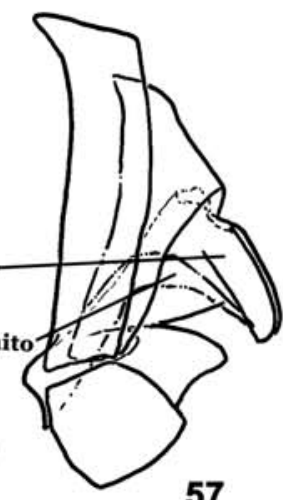

57

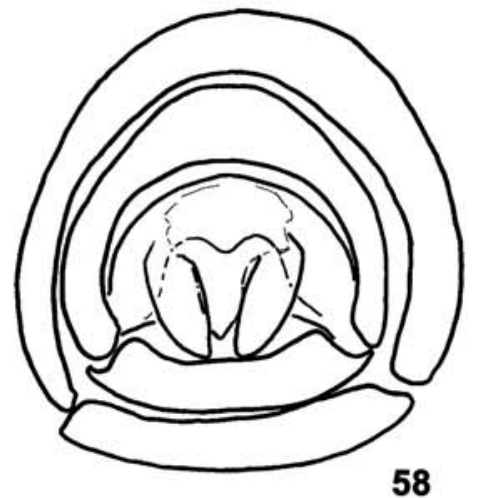

58

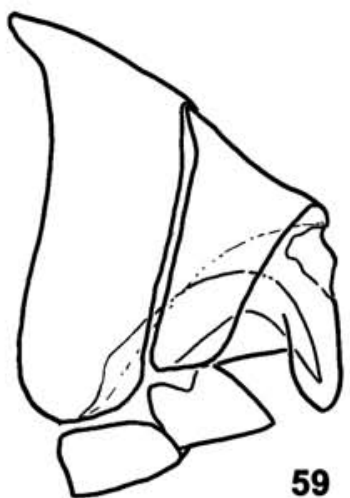

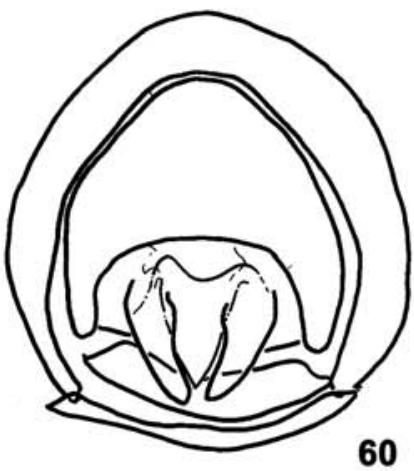

60

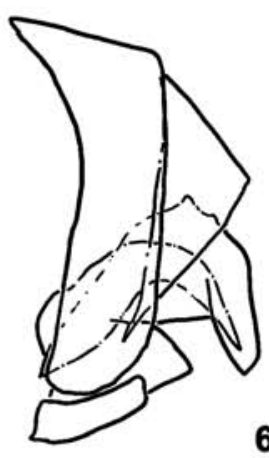

61

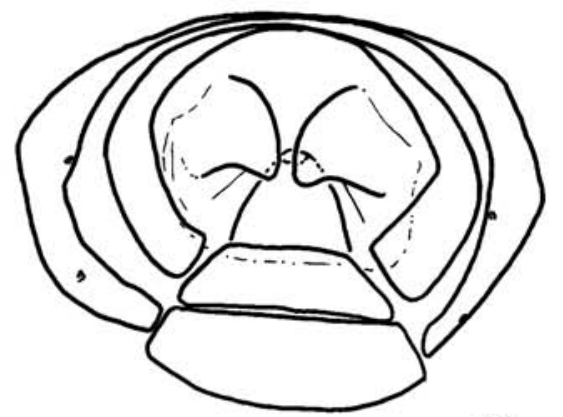

62
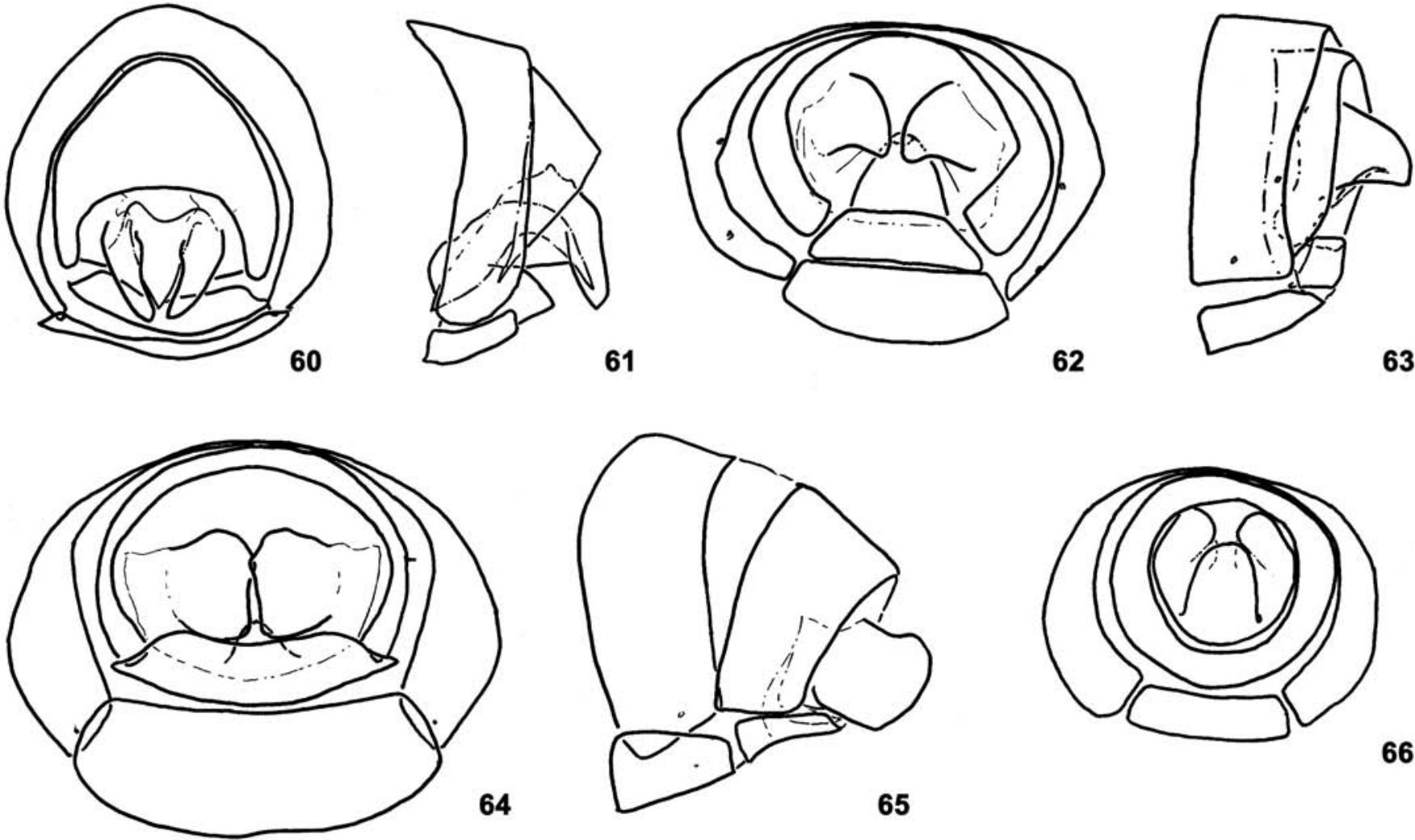

66
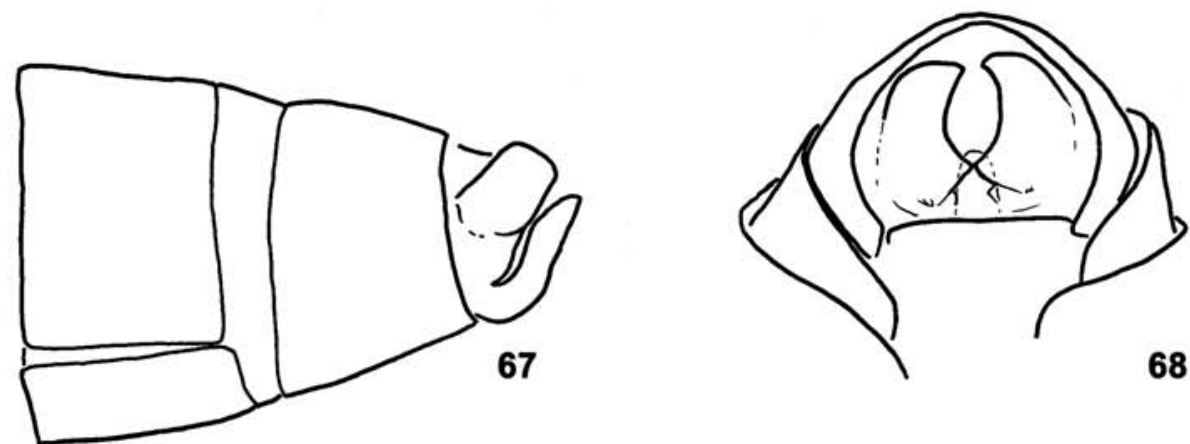

Figs. 56-68. Cercos e oitavo esternito das fêmeas, vista posterior e lateral, respectivamente: 56-57, Acaulona costata Wulp, 1888; 58-59, A. peruviana Townsend, 1913; 60-61, A. erythopyga Sabrosky, 1950; 62-63, Xanthomelanopsis brasiliensis Townsend, 1917; 64-65, Itaxanthomelana grandis Townsend, 1927; 66-67, Euacaulona sumichrasti Townsend, 1908. Cercos e oitavo esternito da fêmea, vista posterior: 68, Melanorophasia minuscula Townsend, 1934. 
partes látero-ventrais da base dos tergitos 3,4 e 5 , cerca de quatro vezes mais longo que largo; sintergito $1+2$, tergitos 3,4 e 5 com uma fileira espaçada de cerdas marginais medianas; $o$ par central dos tergitos 3 e 4 e todas as cerdas do tergito 5 eretas ou suberetas e fortes, as demais recumbidas e mais fracas.

Terminália. Cercos (Figs. 14, 15) com o processo apical mediano estreito na base e alargado em direção ao ápice, este subarredondado e em vista posterior retrodirigido; laterais apicais levemente abauladas e curvadas para dentro, formando uma reentrância antes de alcançar a parte mediana. Edeago (Figs. 38-40): basifalo projetado para o dorso com uma reentrância de onde parte o epifalo membranoso; distifalo contorcido, alargado médio-apicalmente; acrofalo mais estreito e membranoso; ducto espermático interno mais alargado e esclerotinizado médio-apicalmente. Apódema ejaculatório mais longo do que largo.

Distribuição geográfica. Brasil (São Paulo e Santa Catarina).

Comentário. O exemplar de São Paulo apresenta uma protuberância anterior ao processo apical mediano dos cercos. Apesar desta diferença, não foi possível, pelas características externas e demais peças da genitália, separá-lo dos demais exemplares desta espécie.

Etimologia. Homenagem à Sra. Nayr Sforcin.

Material-tipo. Holótipo macho: BRASIL, Santa Catarina: Seara (Nova Teutônia), I-II.1937, F. Plaumann col. (BMNH). Parátipos: idem, 3 machos, 2.I/ 8.IV/ 27.VII.1937 (BMNH).

Material examinado. BRASIL. São Paulo: Ilha dos Búzios, 1 macho, 16.X-4.XI.1963, Exp. Depto. Zool. col. (MZSP).

\section{Mahauiella sforcini sp. nov. \\ (Figs. 5, 16, 17, 35-37)}

Diagnose. Parafrontália pouco mais de um quarto da largura da fronte; pró-fronte pouco mais que um terço da largura da fronte. Antena e arista castanhas levemente alaranjadas; flagelômero pouco mais que o dobro do comprimento do pedicelo. Asa com ângulo formado entre o pecíolo da veia $\mathrm{R} 4+5$ e veia $\mathrm{M}$ com pouco mais de $90^{\circ}$. Abdome cerca de cinco vezes mais longo do que largo.

Comprimento $6,0 \mathrm{~mm}$.

Macho. Cabeça pardo-acastanhada, com pruinosidade amarelo-brilhante; face levemente acinzentada. Parafrontália pouco mais de um quarto da largura da fronte; pró-fronte pouco mais que um terço da largura da fronte; parafaciália cerca de um quarto da largura da fronte. Antena e arista castanhas levemente alaranjadas; flagelômero pouco mais que o dobro do comprimento do pedicelo.

Tórax semelhante ao da espécie anterior, deferindo por: mescla de pruinosidade marrom-ferrugínea na parte posterior do escuto; pernas levemente mais claras nas coxas e base das tíbias posteriores; tarsos e garras tarsais relativamente maiores; ângulo formado entre o pecíolo da célula $\mathrm{R} 5 \mathrm{e}$ a veia $\mathrm{M}$ cerca de pouco mais de $90^{\circ}$.

Abdome semelhante ao da espécie anterior diferindo pelo comprimento, cerca de cinco vezes mais longo do que largo.

Terminália. Difere da espécie anterior pelos cercos (Figs. $16,17)$ com o processo apical mediano mais largo, o estreitamento basal menos acentuado, relativamente mais curto. Edeago (Figs. 35-37): basifalo com a projeção e reentrância mais acentuada e sem o epifalo membranoso; distifalo com a parte médio-apical torcida anteriormente; região do acrofalo com membrana bem desenvolvida; ducto espermático interno transparente. Apódema ejaculatório (Fig. 5) relativamente pequeno.

Distribuição geográfica. Brasil (Santa Catarina).

Material-tipo. Holótipo macho: BRASIL, Santa Catarina: Seara (Nova Teutônia), I-II.1937, F. Plaumann col. (BMNH).

Agradecimentos. Aos responsáveis pelos empréstimos de material: Dr. David Grimald (AMNH), Dr. Nigel Wyatt (BMNH), Dr. Claudio José B. de Carvalho (DZUP), Dr. Norman Woodley (USNM), Dr. James O'Hara (CNCI); Dr. José Albertino Rafael (INPA); Dra. Ana Harada (MPEG). Ao Dr. Ricardo Pinto da Rocha (USP) pelo empréstimo do equipamento óptico. À Dra. Eliana Cancello e ao Dr. José Henrique Guimarães (MZSP) pelo apoio e a este último também pela cessão de bibliografia. À FAPESP pela concessão da bolsa de estudo (Proc. 99/04767-5).

\section{REFERÊNCIAS}

Beingolea, G. O. 1962. Empleo de insecticidas orgánicos en el Perú y posibilidades de reducirlo por medio del control integrado. Revista Peruana de Entomologia Agrícola 5(1): 31-38.

Berry, P. A. 1951. Biology and habits of cotton stainers (Hemiptera: Dysdercus spp.), their natural enemies in South America, and two parasitic flies imported into Puerto Rico. Revista de Entomologia 22(1-3): 329-342.

Blanchard, E. E. 1966. Nuevos triquiopodinos argentinos, parásitos de hemípteros nocivos (Diptera, Gymnosomatidae). Revista de Insvestigaciones Agrícola, Ser. 5 (Pat. Veg.), 3(7): 59-95.

Chan, A. R. \& M. Zapata. 1965. Estudios sobre la biologia y habitos de Acaulona peruvianus T.T. (Tachinidae) un parásito de Dysdercus peruvianus Guen. (Pyrrhocoridae). Anales Científicos de la Universidad Agraria 3: 300-308.

Dupuis, C. 1963. Essai monographique sur les Phasiinae (Diptères Tachinaires parasites de'Hétéroptères). Mémoires du Muséum Nationale d'Histoire Naturelle, ser. A, Zool. 26: 1-461.

Guimarães, J. H. 1971. Family Tachinidae (Larvaevoridae). In: N. Papavero. (ed.). A catalogue of the Diptera of Americas South of the United States. São Paulo, Depto. de Zoologia, Secretaria da Agricultura, v. 104, $333 \mathrm{p}$

Guimarẽes, J. H. 1977. Host-parasite and parasite-host catalogue of South American Tachinidae (Diptera) Archivos de Zoologia do Estado de São Paulo 28(3): 1-131.

Mcalpine, J. F. 1981. Morphology and terminology. In: J. F. Mcalpine et al. (eds.). Manual of Neartic Diptera. Ottawa, Agriculture Canada, Research Branch Monograph 27, vol. I. 674 p.

Mendes, L. O. T. 1938. Lista dos inimigos naturais de Dysdercus spp., observados no Estado de São Paulo. Revista de Entomologia 9(1): 215-217.

Mendes, L. O. T. 1959. Sobre a ocorrência de alguns inimigos naturais de insetos. Anais da Academia Brasileira de Ciencias 31(4): 577-585.

Parker, H. L.; P. A. Berry \& A. S. Guido. 1951. Host-parasites list of insects reared in the South American parasites laboratory during period 1940-1946. Revista Asociación de Ingenieros Agronomos de Montevideo 23(92): 15-112. 
SABrosky, C. W. 1950. Notes on Trichopodini (Diptera, Larvaevoridae), with description of a new parasite of cotton stainers in Porto Rico. Journal of the Washington Academy of Science 40: 361-371.

Sabrosky, C. W. 1951. Correction on Acaulona peruviana Townsend (Diptera, Larvaevoridade). Proceedings of the Entomological Society of Washington 53: 210.

Toma, R. 2002. Acaulona peruviana Townsend, 1913 (Insecta, Diptera): application of Article 75.8 of the Code. Bulletin of Zoological Nomenclature 59(4): 286-288.

Townsend, C. H. T. 1908. The taxonomy of the muscoidean flies, including description of new genera and species. Smithsonian Miscellaneous Collections 51 (= pub. 1803): 1-138.

TownsEnd, C. H. T. 1911. Announcement of further results secured in the study of Muscoid flies. Annals of the Entomological Society of America 4: 127-152.

Townsend, C. H. T. 1912. Descriptions of new genera and species of muscoid flies from the Andean and Pacific coast regions of South America. Proceedings of the United States National Museum 43 (1935): 301-367.

Townsend, C. H. T. 1913. Muscoid parasites of the cotton stainer and other lygaeid. Psyche 20(2): 91-94.

Townsend, C. H. T. 1917a. Miscellaneous muscoid notes and descriptions. Insecutor Inscitiae Menstruus (1916) 4: 121-128.

TownSEND, C. H. T. 1917b. Second paper on Brazilian Muscoidea collected by Herbert H. Smith. Bulletin of the American Museum of Natural History 37(6): 221-233.

Townsend, C. H. T. 1927. Synopse dos gêneros muscoideos da região humida tropical da America, com gêneros e espécies novas. Revista do Museu Paulista 15: 203-385.

TownsEnd, C. H. T. 1928. Insectos que atacan al algodón y a la caña de azúcar en el Perú. Boletin de la Estación Experimental Agrícola de la Sociedad Nacional Agraria 1: 1-29.

TownsEnd, C. H. T. 1934. New Neotropical Oestromuscoid flies. Revista de Entomologia 4(2): 201-212.

Townsend, C. H. T. 1935. New South American Oestroidea (Dipt) Revista de Entomologia 5(2): 216-233.

Townsend, C. H. T. 1936. Manual of Myiology, in twelve parts. Oestroid classification and habits (Gymnosomatidae to Tachinidae). Itaquaquecetuba, Townsend \& Filhos, Pt. III, 249 p.

Townsend, C. H. T. 1937. New fly parasites of Dysdercus. Revista de Entomologia 7(2-3): 316-318.

Townsend, C. H. T. 1938. Manual of Myiology in twelve parts. Oestroid generic diagnose and data (Gymnosomatini to Senostomatini). Itaquaquecetuba, Townsend \& Filhos, Pt. VII, 434 p.

Tschorsnig, H. P. 1985. Taxonomie forstlich wichtiger Parasiten: Untersuchungen zur Struktur des mänlichen Postabdomens de Raupenfliegen (Diptera, Tachinidae). Stuttgarten Beiträge zur Naturkunde 383: 1-137.

Wulp, F. M. van der. 1888. Fam. Muscidae. In: F. D. Godman \& O. Salvin (eds.). Biologia Centrali - Americana. Zoologia, InsectaDiptera. London, vol. 2, 489 p.

Wulp, F. M. van Der. 1892. Diagnoses of new Mexican Muscidae. Tidjschrift voor Entomologie 35: 183-195. 